\title{
LOS MATERIALES IMPRESOS COMERCIALIZADOS POR EL PARTIDO COMUNISTA DE COSTA RICA. UNA CONTRIBUCIÓN DOCUMENTAL $(1931-1948)^{1}$
}

\section{PRINTED MATERIALS COMMERCIALIZED BY THE COMMUNIST PARTY OF COSTA RICA. A DOCUMENTAL CONTRIBUTION (1931-1948)}

\author{
Iván Molina Jiménez
}

RESUMEN

El propósito principal del presente artículo es poner a disposición de los investigadores datos básicos sobre los libros, folletos, periódicos y revistas comercializados por el Partido Comunista de Costa Rica (PCCR) entre 1931 y 1948. Varios de estos materiales fueron publicados localmente por el PCCR, pero otros fueron importados de distintos países de América y Europa. La información aquí presentada es útil para considerar, entre otros temas, las bases teóricas del PCCR, la circulación de textos marxistas en la Costa Rica de las décadas de 1930 y 1940 y algunas de las principales características de esa cultura impresa internacional centrada en la distribución de literatura comunista.

PALABRAS CLAVES: COSTA RICA * PARTIDO COMUNISTA * HISTORIA POLÍTICA * IDENTIDAD CULTURAL $*$ PUBLICACIONES $*$ MARXISMO

\section{ABSTRACT}

The main purpose of this work is to make available to researchers basic data on books, pamphlets, newspapers and magazines sold by the Communist Party of Costa Rica (CPCR) between 1931 and 1948. Several of these materials were published locally by the CPCR, but others were imported from different countries of America and Europe. The information presented here is useful to consider, among other issues, the theoretical underpinnings of CPCR, the circulation of Marxist texts in Costa Rica during the 1930s and 1940s and some of the main characteristics of printed culture focused on the distribution of communist literature.

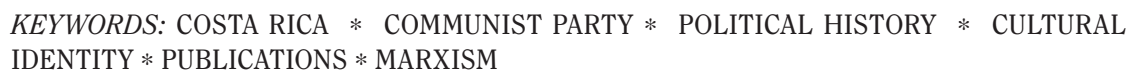

Escuela de Historia y Centro de Investigación en Identidad y Cultura Latinoamericanas (CIICLA), ambos de la Universidad de Costa Rica. ivan.molina@ucr.ac.cr
$1 \quad$ El presente estudio se llevó a cabo en el Centro de Investigación en Identidad y Cultura Latinoamericanas (CIICLA) y fue financiado por la Vicerrectoría de Investigación de la Universidad de Costa Rica. 
El Partido Comunista de Costa Rica (PCCR) jugó un importante papel en la producción, importación y comercialización de libros, folletos, revistas y periódicos durante las décadas de 1930 y 1940. Este es un aspecto que rara vez se considera al estudiar los partidos comunistas latinoamericanos ${ }^{2}$, pese a que constituyó una de sus principales preocupaciones y los obligó a desarrollar estrategias empresariales para asegurar la sostenibilidad financiera de tales actividades. Examinar esta problemática resulta de especial interés, además, porque constituye un privilegiado punto de encuentro de la historia política y la historia de la cultura impresa.

No obstante su relevancia, esta temática no ha sido abordada en los estudios costarricenses que, al analizar el PCCR, han puesto énfasis en el examen de sus alianzas políticas, de su participación en diversas luchas sociales, de sus orígenes intelectuales $y$ del papel jugado por sus máximos dirigentes ${ }^{3}$. Debido al predominio de estos enfoques, actividades fundamentales de la dinámica del PCCR han sido dejadas de lado, como su inserción en la esfera pública y sus esfuerzos por ampliar el mercado cultural de las décadas de 1930 y 1940, mediante la difusión sistemática de materiales impresos específicamente comunistas.

El afán de los comunistas por llevar adelante esas tareas se comprende mejor al tener presente que, desde finales del siglo XIX, Costa Rica comenzó a mejorar sus índices de alfabetización. Según el censo nacional de 1927, la proporción de varones y mujeres de nueve años y más que sabían leer y escribir ascendía, en las ciudades principales a 85,7 por ciento, en las villas o ciudades menores, a 66,8 por ciento, y en

Motta, Rodrigo Patto Sá. "A verdadera patria dos trabalhadores: a URSS e as edições comunistas". Abreu, Marcia y Schapochnik, Nelson (coords.). Cultura letrada no Brasil: objetos e práticas. Campinas, Mercado de Letras-Associação de Leitura do Brasil, 2005: 343-365.

3 Molina Jiménez, Iván. "La participación del Partido Comunista de Costa Rica en la década de 1930: el caso de los comicios de 1934". Historia y Política 13. Madrid, 2005: 176-177. el campo, a 56,4 por ciento ${ }^{4}$. De esta manera, el creciente alfabetismo de los sectores populares abrió la posibilidad de alcanzarlos mediante diversos tipos de materiales impresos, que promovían los objetivos, visiones de mundo, valores e intereses de los comunistas costarricenses $y$ de sus camaradas del resto del mundo.

El período considerado se inicia en 1931 porque, en junio de ese año, fue fundado el PCCR, $y$ termina en 1948 cuando, tras la guerra civil de ese año, el PCCR fue ilegalizado ${ }^{5}$. La relevancia del caso costarricense se relaciona, precisamente, con el hecho de que, a diferencia del resto de Centroamérica, en Costa Rica el partido permaneció como una organización legal por casi veinte años, participó periódicamente en los comicios y consiguió capturar asientos en algunas de las principales municipalidades del país y en el Congreso. En el período bajo estudio, el PCCR compitió electoralmente con dos nombres: Bloque de Obreros y Campesinos (BOC) entre 1931 y 1943, y Partido Vanguardia Popular (PVP) entre 1943 y $1948^{6}$.

A tono con la política internacional del Comintern ${ }^{7}$, el PCCR, a partir de 1935, se caracterizó por una orientación claramente reformista. En tales circunstancias, no sorprende que, a partir de 1941, los comunistas empezaran a acercarse al gobernante Partido Republicano Nacional (PRN), que impulsaba un amplio programa de cambio institucional (establecimiento

Molina, Iván y Palmer, Steven. "Popular Literacy in a Tropical Democracy: Costa Rica 1850-1950". Past and Present 184. 2004: 194.

5 Contreras, Gerardo y Cerdas, José Manuel. Los años 40's: historia de una política de alianzas. San José: Editorial Porvenir, 1988.

6 Molina Jiménez, Iván. "El desempeño electoral del Partido Comunista de Costa Rica (1931-1948)". Revista Parlamentaria 7 (1), abril. San José, 1999: 491-521.

7 Caballero, Manuel. Latin American and the Comintern, 1919-1943. Cambridge. Cambridge University Press, 1986: 49-51, 122-133; FornetBetancourt, Raúl. Transformaciones del marxismo. Historia del marxismo en América Latina. México. Plaza y Valdés, 2001: 172-176. 
del seguro social, incorporación de un capítulo de garantías sociales en la Constitución y aprobación de un código laboral). La aproximación culminó en una alianza formal a partir de 1943, que contribuyó a polarizar la política costarricense, proceso que culminó en el conflicto armado de $1948^{8}$.

Dada la democracia existente en Costa Rica, el PCCR pudo impulsar, de manera libre y abierta, una decidida política de producción de materiales impresos, $y$ de importación de libros, folletos y revistas provenientes de distintos lugares de Europa y América. Dicha actividad era fundamental: en contraste con otros países latinoamericanos, cuyos partidos comunistas tenían la capacidad de financiar la traducción e impresión de obras publicadas originalmente en idiomas diferentes del español ${ }^{9}$, el PCCR era demasiado pequeño - en términos del número de militantes y simpatizantes- para poder costear una práctica de esa índole.

En estudios recientes, hemos analizado diversos aspectos relacionados con la producción, importación y comercialización de los materiales impresos que llevó a cabo el PCCR ${ }^{10}$. $\mathrm{Si}$ bien algunos de estos materiales han sido ampliamente utilizados como fuentes de información por los investigadores, rara vez son considerados como objetos de estudio en sí mismos. Por esta razón, hemos creído conveniente poner a disposición de los académicos interesados en esta problemática los anexos siguientes, en los que se consignan datos básicos sobre las publicaciones propias realizadas por el PCCR y las que importaron de otros países.

En el Anexo 1, se presentan los periódicos y revistas publicados por el PCCR o vinculados con este partido; en el 2 , se recopilan

Molina Jiménez, Iván. Los pasados de la memoria. El origen de la reforma social en Costa Rica (19381943). Heredia. Editorial Universidad Nacional, 2008: 227-266, 285-301.

Motta. A verdadera patria... pp. 343-365. los libros $y$ folletos publicados por el PCCR en Costa Rica; $y$ en los numerados del 3 al 5, se identifican los materiales importados por el PCCR, tanto los que tenía a la venta, como los que llegaron a formar parte de la biblioteca circulante del PCCR. Establecida en 1946, esta biblioteca alquilaba los materiales que disponía (se cobraban diez céntimos semanales por obra). En todos los anexos, el precio se indica en colones y céntimos (cien céntimos equivalen a un colón). El tipo de cambio, entre 1931 y 1936, osciló entre 4 y 6 colones por dólar; a partir de 1937, se estabilizó en 5,6 colones por dólar ${ }^{11}$. En los dos primeros anexos, los materiales están ordenados según la fecha aproximada en que fueron publicados; en los tres últimos anexos, se les ordena según la fecha en que fueron anunciados.

La información sobre los materiales impresos importados procede del periódico del PCCR, Trabajo, que circuló mensualmente entre 1931 y 1932, y una vez a la semana a partir de 1933. Esos datos presentan algunas limitaciones que conviene indicar con algún detalle. Primero, en ningún momento los comunistas publicaron un catálogo completo de los títulos que tenían a la venta. Su práctica consistió más bien en publicar listas parciales, a medida que les llegaban obras nuevas. Tampoco solían anunciar, de inmediato, todas las novedades y se limitaban — quizás por motivos de espacioa destacar los títulos que podían capturar la atención de los potenciales compradores.

En segundo término, en esas listas se solía consignar apenas el título de la obra (aunque no siempre de manera exacta $y$ completa) $y$ a veces también, el apellido y el nombre del autor, y el precio. Por lo general, se tendía a diferenciar a las revistas de los libros, pero no a estos últimos de los folletos. Más raramente se brindaba información sobre características particulares de la edición, como el lugar de impresión, la editorial o el tipo de empaste. En algunas ocasiones, al lado del título se señalaba

11

Bulmer-Thomas, Victor. La economía politica de Centroamérica desde 1920. San José. Banco Centroamericano de Integración Económica, 1989: $68,85,136$. 
de qué trataba la obra y por qué era importante que los militantes y simpatizantes del PCCR la compraran y leyeran. Con excepción de cinco casos (una biografía de Lenin, un texto sobre el ejército soviético, una historia del Partido Comunista de la URSS, el estudio de Stalin sobre el marxismo y la cuestión nacional y el Manifiesto comunista), el PCCR parece haber comercializado sólo una edición de cada una de las obras importadas.

Para enfrentar las dificultades anteriores, se elaboró una base de datos con la información publicada en Trabajo y posteriormente, se hizo una labor de reconstrucción de los datos exactos y completos de cada uno de los títulos anunciados a partir de una revisión de los catálogos virtuales de diversas bibliotecas costarricenses, estadounidenses, mexicanas, argentinas, chilenas, uruguayas y españolas. De los libros y folletos importados, no fue posible completar los datos de unos pocos títulos. Para la mayoría de las obras, sólo se identificó una edición que coincide con la fecha en que fueron anunciadas por primera vez en Trabajo. En relación con algunos libros y folletos, existe más de una edición que podría coincidir. En relación con estos casos, se consignó la edición que, a juzgar por su presencia en los inventarios de bibliotecas costarricenses, era más probable que hubiera circulado en Costa Rica. Los datos reconstruidos se consignan entre paréntesis cuadrados con el fin de que puedan ser diferenciados fácil $y$ adecuadamente.

En fin, en los anexos siguientes, se proporciona una información que puede ser útil para investigadores de distintas disciplinas, interesados en conocer, entre otros temas, las bases teóricas del PCCR, la circulación de textos marxistas en la Costa Rica de las décadas de 1930 y 1940 y algunas características de esa cultura impresa internacional centrada en la producción, distribución y comercialización de literatura comunista. La recuperación de estos materiales es fundamental, además, para empezar a aproximarse a dimensiones estratégicas de la cultura comunista costarricense, forjada en los decenios indicados, que han tendido a quedar en el olvido.

ANEXO 1

PERIÓDICOS Y REVISTAS VINCULADOS CON EL PARTIDO COMUNISTA DE COSTA RICA (1931-1948)

\begin{tabular}{|c|c|c|c|c|c|c|}
\hline NOMBRE & LUGAR & $\begin{array}{l}\text { NÚMEROS } \\
\text { IMPRESOS }\end{array}$ & $\begin{array}{l}\text { AÑOS EN QUE } \\
\text { SE PUBLICÓ }\end{array}$ & PRECIO & PERIODICIDAD & PÁGINAS \\
\hline Trabajo & San José & 777 & 1931-48 & $0,10-0,20$ & Semanal & $4-8$ \\
\hline $\begin{array}{l}\text { Trabajo (suplemento } \\
\text { en inglés) }\end{array}$ & San José & 1 ? & 1934 & Gratis & & \\
\hline La Voz Sindical & San José & 1 ? & 1934 & & & \\
\hline La Lucha & Puntarenas & 1 ? & 1940 & & & \\
\hline Vanguardia & San José & 12 & $1941-42$ & 0,40 & $\begin{array}{c}\text { Mensual/ } \\
\text { Bimensual }\end{array}$ & $18-22$ \\
\hline Combate & San José & $3 ?$ & $1943-44$ & & & 8 \\
\hline Trinchera & San José & $3 ?$ & $1946-47$ & 0,10 & & 8 \\
\hline Vanguardia & San José & 1 ? & 1947 & 0,5 & & \\
\hline
\end{tabular}

* $\quad$ Cinco céntimos de colón equivalían en promedio a un centavo de dólar.

Fuente: Molina Jiménez, Iván. "Los comunistas como empresarios. La gestión del periódico Trabajo. Costa Rica (1931-1948)". Revista de Historia de América 140. México, 2009, en prensa; Cerdas, Rodolfo. La hoz y el machete. La Internacional Comunista, América Latina y la revolución en Centroamérica. San José. Editorial Universidad Estatal a Distancia, 1986: 334-335; Trabajo, 16 de noviembre de 1940: 2; 5 de septiembre de 1942: 4; 11 de noviembre de 1944: 4; 18 de diciembre de 1945: 3; 16 de noviembre de 1946: 4; 22 de marzo de 1947: 3; 9 de agosto de 1947: 5; Vanguardia (19411942); Combate, 7 de noviembre de 1944: 2; Trinchera, 15 de junio de 1946: 1; United States National Archives, Decimal Files, 818.00/1447. February 23, 1934: 6. 
ANEXO 2

LIBROS Y FOLLETOS PUBLICADOS POR EL PARTIDO COMUNISTA DE COSTA RICA (1931-1948)

\begin{tabular}{|c|c|c|c|c|c|c|}
\hline AÑO & AUTOR & TÍTULO & LUGAR & IMPRENTA & PÁGINAS & PRECIO \\
\hline 193?-??-?? & & $\begin{array}{l}\text { ¿Qué es lo que quiere el } \\
\text { Partido Comunista? }\end{array}$ & San José & La Tribuna & & \\
\hline 1933-01-28 & Lyra, Carmen & El grano de oro y el peón & San José & Tormo & 22 & 0,10 \\
\hline $1934-06-24$ & $\begin{array}{l}\text { Mora Valverde, } \\
\text { Manuel }\end{array}$ & $\begin{array}{l}\text { Discurso pronunciado en } \\
\text { la cámara el } 12 \text { de junio de } \\
1934 \text { contra la demagogia } \\
\text { de Jorge Volio y definien- } \\
\text { do posiciones del Partido } \\
\text { Comunista }\end{array}$ & San José & La Tribuna & 28 & 0,10 \\
\hline $1935-12-15$ & $\begin{array}{l}\text { Fallas Sibaja, } \\
\text { Carlos Luis }\end{array}$ & $\begin{array}{l}\text { El peligro de la dictadura. } \\
\text { Las elecciones y la organi- } \\
\text { zación sindical }\end{array}$ & San José & Falcó & 40 & 0,25 \\
\hline $1936-00-00$ & Lyra, Carmen & $\begin{array}{l}\text { Los cuentos de mi tía Pan- } \\
\text { chita }\end{array}$ & San José & $\begin{array}{l}\text { Soley y } \\
\text { Valverde }\end{array}$ & 160 & 2,5 \\
\hline 1937-00-00 & & $\begin{array}{l}\text { Estatutos del Partido Co- } \\
\text { munista de Costa Rica }\end{array}$ & San José & Cartín & & \\
\hline $1937-06-26$ & $\begin{array}{l}\text { Mora Valverde, } \\
\text { Manuel }\end{array}$ & $\begin{array}{l}\text { Tres discursos en defensa } \\
\text { de la democracia }\end{array}$ & San José & La Tribuna & 60 & 0,25 \\
\hline $1938-00-00$ & $\begin{array}{l}\text { Bloque de Obreros } \\
\text { y Campesinos }\end{array}$ & Instrucciones para fiscales & San José & La Tribuna & & \\
\hline $1939-01-28$ & $\begin{array}{l}\text { Mora Valverde, } \\
\text { Manuel }\end{array}$ & $\begin{array}{l}\text { Por la afirmación de } \\
\text { nuestra democracia, por } \\
\text { el progreso y bienestar de } \\
\text { nuestra nación }\end{array}$ & San José & & 24 & 0,10 \\
\hline $1939-12-23$ & $\begin{array}{l}\text { Mora Valverde, } \\
\text { Manuel }\end{array}$ & $\begin{array}{l}\text { Dos discursos en respuesta } \\
\text { a los falsos defensores de la } \\
\text { democracia y de la inde- } \\
\text { pendencia de las pequeñas } \\
\text { naciones }\end{array}$ & San José & $\begin{array}{l}\text { Comité de } \\
\text { Prensa del } \\
\text { PCCR }\end{array}$ & 30 & 0,10 \\
\hline $1940-10-12$ & $\begin{array}{l}\text { Mora Valverde, } \\
\text { Manuel }\end{array}$ & $\begin{array}{l}\text { Imperialismo: nuestra } \\
\text { soberanía frente al Departa- } \\
\text { mento de Estado }\end{array}$ & San José & & 136 & 0,25 \\
\hline 1941-01-11 & Sáenz, Carlos Luis & Raíces de esperanza & San José & $\begin{array}{l}\text { Imprenta } \\
\text { Española }\end{array}$ & 64 & 0,25 \\
\hline 1941-07-19 & $\begin{array}{l}\text { Fallas Sibaja, } \\
\text { Carlos Luis }\end{array}$ & Mamita Yunai & San José & $\begin{array}{l}\text { Soley y } \\
\text { Valverde }\end{array}$ & 248 & 2 \\
\hline 1943-04-10 & $\begin{array}{l}\text { Mora Valverde, } \\
\text { Manuel }\end{array}$ & $\begin{array}{l}\text { Línea política y programa } \\
\text { de emergencia del Partido } \\
\text { Comunista; comentarios } \\
\text { explicativos }\end{array}$ & San José & & 39 & \\
\hline 1944-??-?? & $\begin{array}{l}\text { Ferreto Segura, } \\
\text { Arnoldo }\end{array}$ & $\begin{array}{l}\text { Primer Congreso Extraordi- } \\
\text { nario del Partido Vanguar- } \\
\text { dia Popular. Informe sobre } \\
\text { la situación política nacio- } \\
\text { nal e internacional. }\end{array}$ & San José & Cartín & 19 & \\
\hline
\end{tabular}


ANEXO 2 (CONTINUACIÓN)

LIBROS Y FOLLETOS PUBLICADOS POR EL PARTIDO COMUNISTA DE COSTA RICA (1931-1948)

\begin{tabular}{|c|c|c|c|c|c|c|}
\hline AÑO & AUTOR & TÍTULO & LUGAR & IMPRENTA & PÁGINAS & PRECIO \\
\hline 1944-??-?? & $\begin{array}{l}\text { Partido Vanguardia } \\
\text { Popular }\end{array}$ & $\begin{array}{l}\text { Trece aniversario de dos } \\
\text { informes: circulación y } \\
\text { finanzas }\end{array}$ & San José & Cartín & & \\
\hline 1944-11-25 & $\begin{array}{l}\text { Partido Vanguardia } \\
\text { Popular }\end{array}$ & $\begin{array}{l}\text { Nuevos estatutos de } \\
\text { Vanguardia Popular }\end{array}$ & & & & 0,25 \\
\hline 1945-??-?? & $\begin{array}{l}\text { Mora Valverde, } \\
\text { Manuel }\end{array}$ & $\begin{array}{l}\text { No estamos satisfechos con } \\
\text { algunas actuaciones de este } \\
\text { gobierno }\end{array}$ & San José & La Tribuna & 30 & \\
\hline 1945-??-?? & $\begin{array}{l}\text { Mora Valverde, } \\
\text { Manuel }\end{array}$ & $\begin{array}{l}\text { Por qué Vanguardia } \\
\text { Popular sigue apoyando } \\
\text { al Gobierno: importancia } \\
\text { de las elecciones de medio } \\
\text { período }\end{array}$ & San José & La Tribuna & & \\
\hline $1945-? ?-? ?$ & & $\begin{array}{l}\text { Por qué lucha el Partido } \\
\text { Vanguardia Popular }\end{array}$ & San José & La Tribuna & 16 & \\
\hline 1945-09-01 & $\begin{array}{l}\text { Comité Seccional } \\
\text { de San José del } \\
\text { PVP }\end{array}$ & $\begin{array}{l}\text { ¿Hemos tenido una línea } \\
\text { política incorrecta? }\end{array}$ & San José & $\begin{array}{l}\text { Ediciones } \\
\text { Vanguardia }\end{array}$ & 15 & 0,10 \\
\hline $1946-09-23$ & $\begin{array}{l}\text { Ferreto Segura, } \\
\text { Arnoldo y Mora } \\
\text { Valverde, Manuel }\end{array}$ & $\begin{array}{l}\text { La Unión Soviética ante la } \\
\text { nueva guerra imperialista }\end{array}$ & & & & \\
\hline $1946-09-23$ & $\begin{array}{l}\text { Mora Valverde, } \\
\text { Manuel y Ferreto } \\
\text { Segura, Arnoldo }\end{array}$ & La URSS frente al Eje & & & & \\
\hline 1947-??-?? & $\begin{array}{l}\text { Partido Vanguardia } \\
\text { Popular }\end{array}$ & $\begin{array}{l}\text { Informe sobre la situación } \\
\text { política nacional e interna- } \\
\text { cional (III Congreso Nacio- } \\
\text { nal ordinario) }\end{array}$ & San José & $\begin{array}{l}\text { Ediciones } \\
\text { Vanguardia }\end{array}$ & 24 & \\
\hline $1947-02-08$ & $\begin{array}{l}\text { Fallas Sibaja, } \\
\text { Carlos Luis }\end{array}$ & Gentes y gentecillas & San José & & 319 & \\
\hline 1947-03-11 & $\begin{array}{l}\text { Ferreto Segura, } \\
\text { Arnoldo }\end{array}$ & $\begin{array}{l}\text { Los principios de organiza- } \\
\text { ción del Partido Vanguardia } \\
\text { Popular }\end{array}$ & San José & $\begin{array}{l}\text { Ediciones } \\
\text { Vanguardia }\end{array}$ & 24 & \\
\hline 1948-??-?? & & $\begin{array}{l}\text { ¿Cómo y por qué cayó la } \\
\text { democracia en Costa Rica? }\end{array}$ & San José & & 20 & \\
\hline 1948-12-?? & $\begin{array}{l}\text { Comisión Política } \\
\text { de Vanguardia } \\
\text { Popular }\end{array}$ & $\begin{array}{l}\text { Los sucesos de Costa Rica. } \\
\text { Un examen de la Guerra } \\
\text { Civil }\end{array}$ & & & 32 & \\
\hline
\end{tabular}

Fuente: Trabajo (1931-1948); Sistema Nacional de Bibliotecas de Costa Rica. "Catálogo general"; Sistema de Bibliotecas, Información y Documentación de la Universidad de Costa Rica. "Catálogo general"; Online Computer Library Center. "WorldCat". 
ANEXO 3

REVISTAS Y PERIÓDICOS IMPORTADOS POR EL PARTIDO COMUNISTA DE COSTA RICA (1931-1948)

\begin{tabular}{|c|c|c|c|c|}
\hline FECHA & TÍTULO & LUGAR & PERIODICIDAD & PRECIO \\
\hline $1931-11-28$ & Mundo obrero. Revista mensual ilustrada & [Nueva York] & [Mensual] & \\
\hline 1933-01-07 & La Internacional Comunista & [Barcelona] & [Mensual] & {$[0,75]$} \\
\hline $1933-09-10$ & La Internacional Comunista & [Barcelona] & [Mensual] & 0,75 \\
\hline $1934-06-17$ & La Internacional Comunista & [Barcelona] & [Mensual] & \\
\hline 1935-08-04 & La Internacional Comunista & [Barcelona] & [Mensual] & 0,50 \\
\hline $1935-10-20$ & Información Internacional & [Valencia] & [Semanal] & 0,20 \\
\hline $1935-10-20$ & La correspondencia sindical internacional & [Barcelona] & [Semanal] & 0,15 \\
\hline $1935-10-20$ & La Internacional Comunista & [Barcelona] & [Mensual] & 0,25 \\
\hline $1935-10-20$ & $\begin{array}{l}\text { Revista universal (la mejor fuente de } \\
\text { información extranjera) }\end{array}$ & [Barcelona] & [Mensual] & 0,20 \\
\hline $1938-08-13$ & $\begin{array}{l}\text { Futuro. Revista de la Universidad Obrera de } \\
\text { México }\end{array}$ & [México] & [Mensual] & 0,50 \\
\hline 1938-08-13 & $\begin{array}{l}\text { UO Revista de la Universidad Obrera de } \\
\text { México }\end{array}$ & [México] & [Trimestral] & 1,50 \\
\hline 1938-09-10 & $\begin{array}{l}\text { Futuro. Revista de la Universidad Obrera de } \\
\text { México }\end{array}$ & [México] & [Mensual] & 0,50 \\
\hline 1938-09-10 & $\begin{array}{l}\text { UO Revista de la Universidad Obrera de } \\
\text { México [UO Revista de Cultura Moderna] }\end{array}$ & [México] & [Trimestral] & 1,50 \\
\hline $1942-08-01$ & Actualidades & [México] & [Mensual] & \\
\hline 1942-08-08 & Actualidades & [México] & [Mensual] & \\
\hline $1942-08-08$ & Fundamentos & [La Habana] & [Mensual] & {$[0,75]$} \\
\hline $1942-10-24$ & Futuro & [México] & [Mensual] & 0,5 \\
\hline $1942-11-21$ & Fundamentos & [La Habana] & [Mensual] & 0,75 \\
\hline 1944-01-08 & Fundamentos & [La Habana] & [Mensual] & 0,75 \\
\hline 1944-06-17 & Dialéctica & [La Habana] & [Bimensual] & {$[1,75]$} \\
\hline 1944-07-01 & [La] Literatura Internacional & [Moscú] & [Mensual] & \\
\hline 1944-07-29 & [La] Literatura Internacional & [Moscú] & [Mensual] & \\
\hline $1944-07-29$ & Dialéctica & [La Habana] & [Bimensual] & \\
\hline $1944-07-29$ & Gaceta del Caribe & [La Habana] & [Mensual] & \\
\hline
\end{tabular}


ANEXO 3 (CONTINUACIÓN)

REVISTAS Y PERIÓDICOS IMPORTADOS POR EL PARTIDO COMUNISTA DE COSTA RICA (1931-1948)

\begin{tabular}{|c|c|c|c|c|}
\hline FECHA & TÍTULO & LUGAR & PERIODICIDAD & PRECIO \\
\hline $1944-08-12$ & [La] Literatura Internacional & [Moscú] & [Mensual] & \\
\hline $1944-08-12$ & Gaceta del Caribe & [La Habana] & [Mensual] & \\
\hline 1944-09-23 & [La] Literatura Internacional & [Moscú] & [Mensual] & \\
\hline $1944-09-23$ & Dialéctica & [La Habana] & [Bimensual] & \\
\hline $1944-09-23$ & Fundamentos & [La Habana] & [Mensual] & \\
\hline 1944-09-30 & Dialéctica & [La Habana] & [Bimensual] & \\
\hline 1944-09-30 & Fundamentos & [La Habana] & [Mensual] & \\
\hline $1945-02-10$ & Cultura soviética & [México] & [Mensual] & \\
\hline $1945-02-10$ & Fundamentos (política internacional) & [La Habana] & [Mensual] & \\
\hline $1945-02-10$ & Gaceta del Caribe La (literaria) & [La Habana] & [Mensual] & \\
\hline $1945-05-26$ & Dialéctica & [La Habana] & [Bimensual] & 1,75 \\
\hline $1945-05-26$ & Fundamentos & [La Habana] & [Mensual] & 0,75 \\
\hline $1945-05-26$ & Revista Mensual Ilustrada & [México] & [Mensual] & 1 \\
\hline 1945-08-04 & Cultura soviética & [México] & [Mensual] & \\
\hline $1945-08-11$ & $\begin{array}{l}\text { Boletín de Información de la Embajada de la } \\
\text { URSS en México }\end{array}$ & [México] & & \\
\hline $1945-08-11$ & Cultura soviética & [México] & [Mensual] & \\
\hline 1945-09-01 & Cultura soviética & [México] & [Mensual] & \\
\hline 1945-09-01 & Dialéctica & [La Habana] & [Bimensual] & \\
\hline 1945-09-01 & Fundamentos & [La Habana] & [Mensual] & \\
\hline 1945-09-08 & Cultura soviética & [México] & [Mensual] & \\
\hline 1945-09-08 & Dialéctica & [La Habana] & [Bimensual] & \\
\hline 1945-09-08 & Fundamentos & [La Habana] & [Mensual] & \\
\hline 1945-09-22 & Cultura soviética & [México] & [Mensual] & \\
\hline 1945-09-29 & Cultura soviética & [México] & [Mensual] & \\
\hline 1946-01-05 & Cultura soviética & [México] & [Mensual] & \\
\hline 1946-02-09 & Cultura soviética & [México] & [Mensual] & \\
\hline
\end{tabular}

Continúa... 
ANEXO 3 (CONTINUACIÓN)

REVISTAS Y PERIÓDICOS IMPORTADOS POR EL PARTIDO COMUNISTA DE COSTA RICA (1931-1948)

\begin{tabular}{|c|c|c|c|c|}
\hline FECHA & TÍTULO & LUGAR & PERIODICIDAD & PRECIO \\
\hline $1946-02-23$ & Cultura soviética & [México] & [Mensual] & \\
\hline 1946-03-09 & Cultura soviética & [México] & [Mensual] & \\
\hline $1946-03-23$ & Cultura soviética & [México] & [Mensual] & \\
\hline $1946-06-08$ & Cultura soviética & [México] & [Mensual] & \\
\hline 1946-06-22 & Futuro & [México] & [Mensual] & \\
\hline $1946-07-06$ & Cultura soviética & [México] & [Mensual] & \\
\hline $1946-08-10$ & $\begin{array}{l}\text { Boletín de información de la URSS [URSS; } \\
\text { boletín de información]* }\end{array}$ & [La Habana] & [Quincenal] & \\
\hline $1946-08-10$ & Cultura soviética* & [México] & [Mensual] & \\
\hline $1946-08-10$ & Futuro* & [México] & [Mensual] & \\
\hline $1946-08-10$ & $\begin{array}{l}\text { Revista } 1946 \text { [1946: revista mensual hecha } \\
\text { por pintores, grabadores, escritores, } \\
\text { dibujantes, fotógrafos, en defensa del } \\
\text { progreso social de México]* }\end{array}$ & [México] & [Mensual] & \\
\hline $1946-08-10$ & $\begin{array}{l}\text { Revista de la Internacional Comunista [La } \\
\text { Internacional Comunista: órgano del Comité } \\
\text { Ejecutivo de la Internacional Comunista]* }\end{array}$ & $\begin{array}{l}\text { [Madrid, } \\
\text { Barcelona, } \\
\text { París, México] }\end{array}$ & [Mensual] & \\
\hline 1946-09-14 & Cultura Soviética & [México] & [Mensual] & \\
\hline 1946-09-22 & $\begin{array}{l}\text { Boletín de información de la URSS [URSS; } \\
\text { boletín de información] }\end{array}$ & [La Habana] & [Quincenal] & \\
\hline $1946-09-22$ & Cultura Soviética & [México] & [Mensual] & \\
\hline 1946-09-22 & Dialéctica & [La Habana] & [Bimensual] & \\
\hline 1946-09-22 & Futuro & [México] & [Mensual] & \\
\hline 1946-09-22 & $\begin{array}{l}\text { Tiempo [Revista Mexicana de Ciencias } \\
\text { Sociales y Letras] }\end{array}$ & [México] & [Mensual] & \\
\hline $1947-02-22$ & Cultura Soviética & [México] & [Mensual] & \\
\hline $1947-02-22$ & Fundamentos & [La Habana] & [Mensual] & \\
\hline
\end{tabular}

*Las alquilaba la biblioteca circulante del PCCR.

Fuente: Trabajo (1931-1948); Sistema Nacional de Bibliotecas de Costa Rica, "Catálogo general". Sistema de Bibliotecas, Información y Documentación de la Universidad de Costa Rica, "Catálogo general". Online Computer Library Center, "WorldCat”. Biblioteca Nacional de España, "El Buscón”. Dirección General de Bibliotecas de la Universidad Nacional Autónoma de México, "Catálogo". Biblioteca Nacional de Argentina, "Catálogo". Biblioteca Nacional de Uruguay, "Catálogo". Biblioteca del Congreso Nacional de Chile, "Catálogo". 


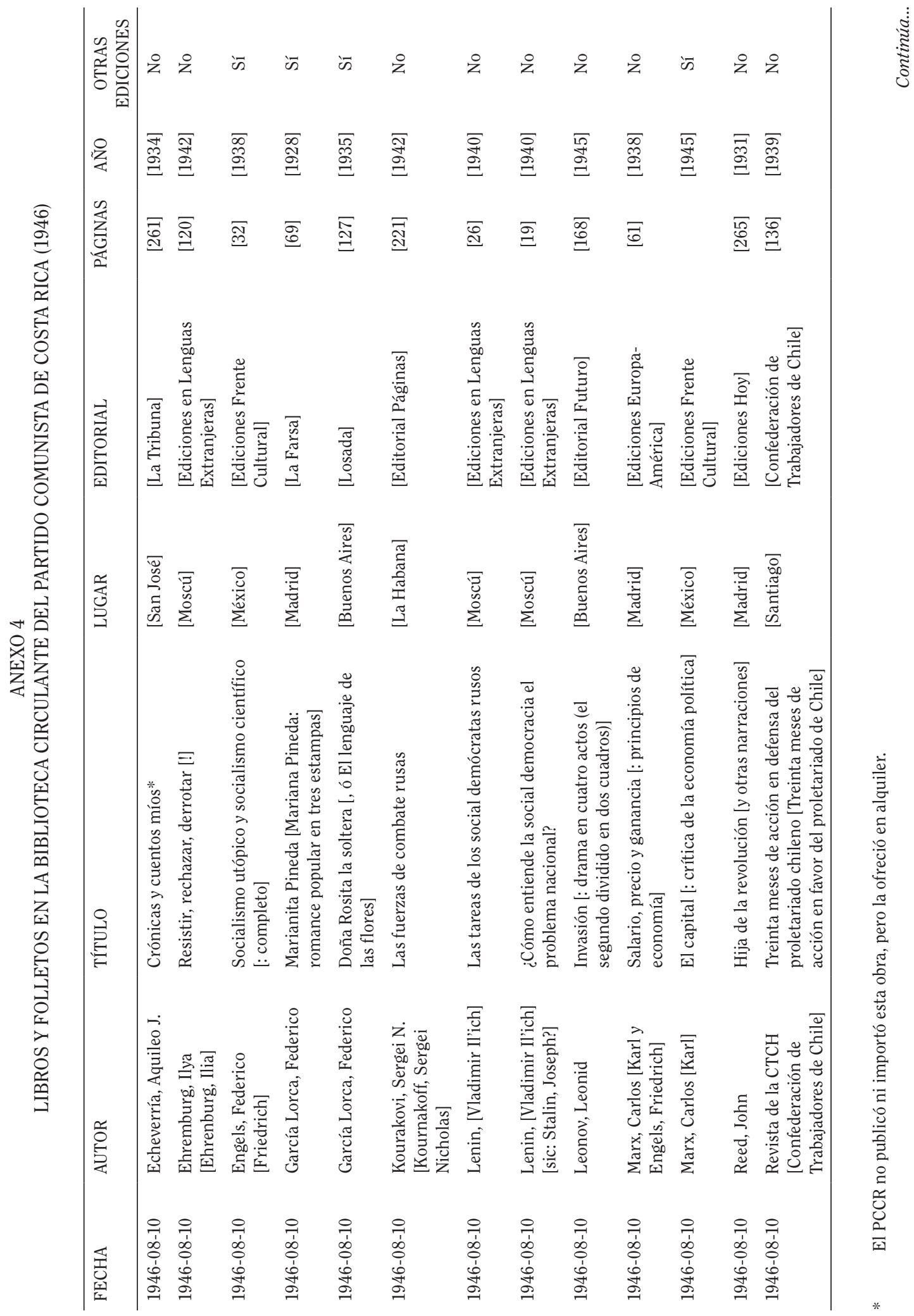




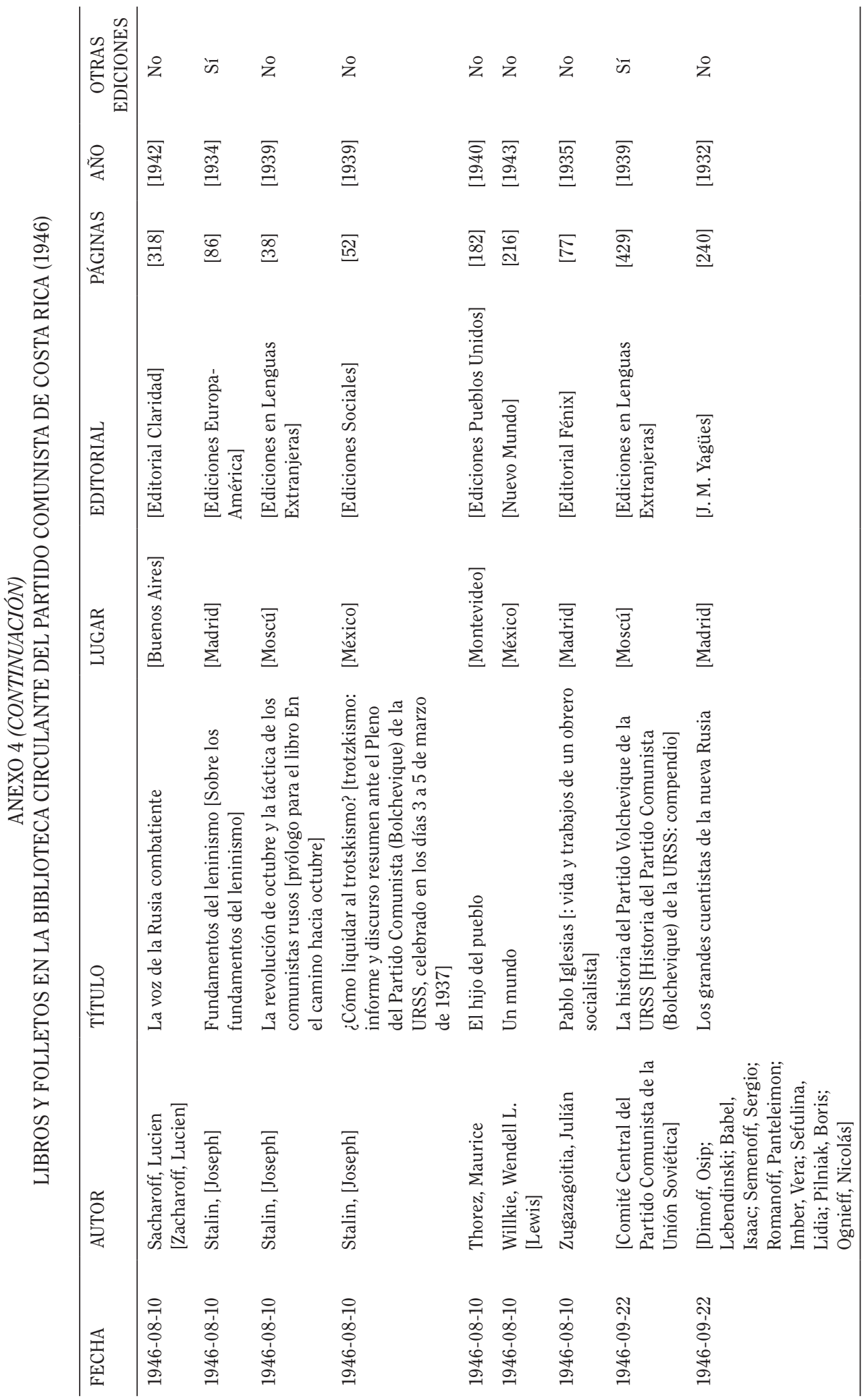




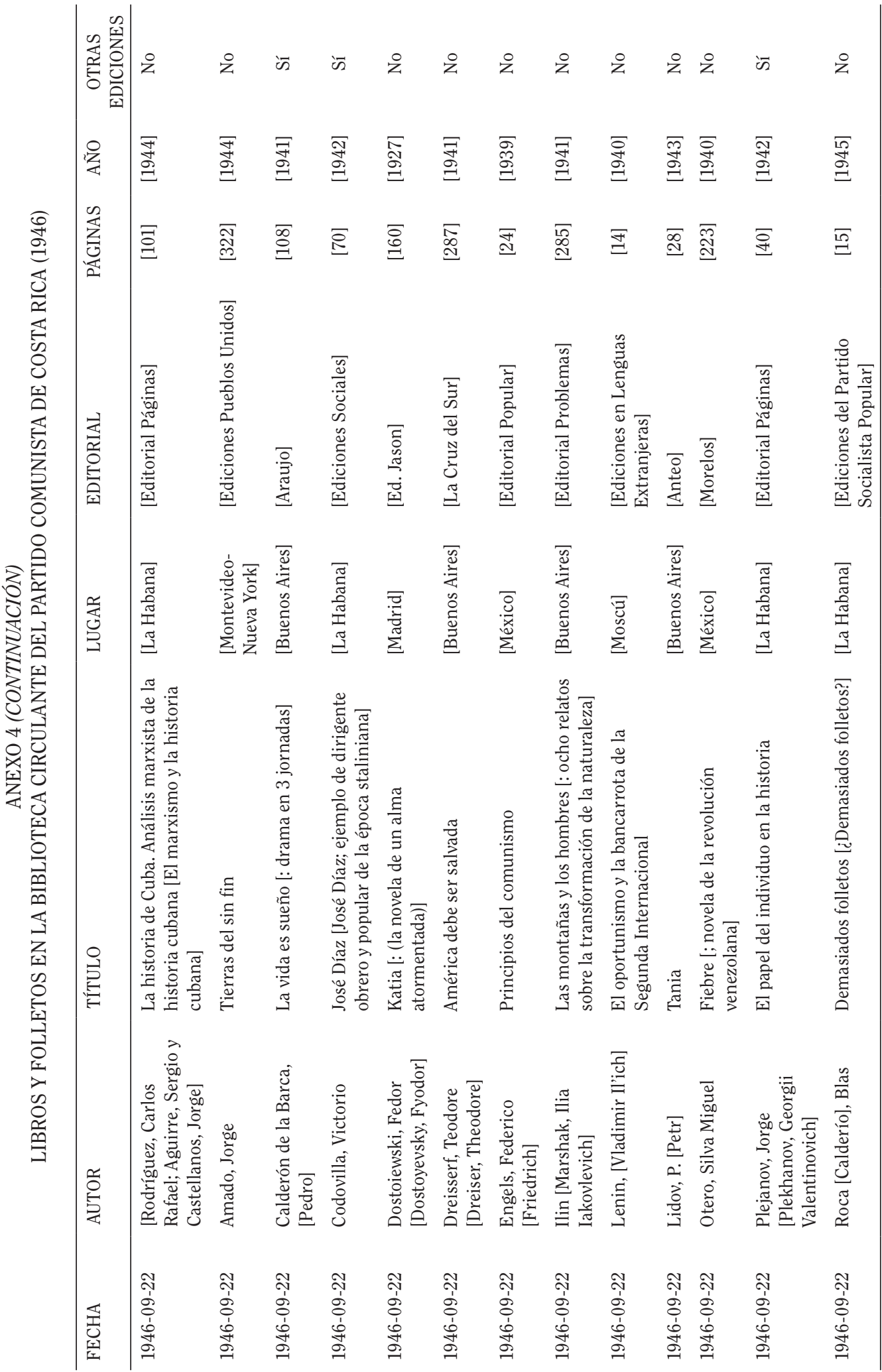




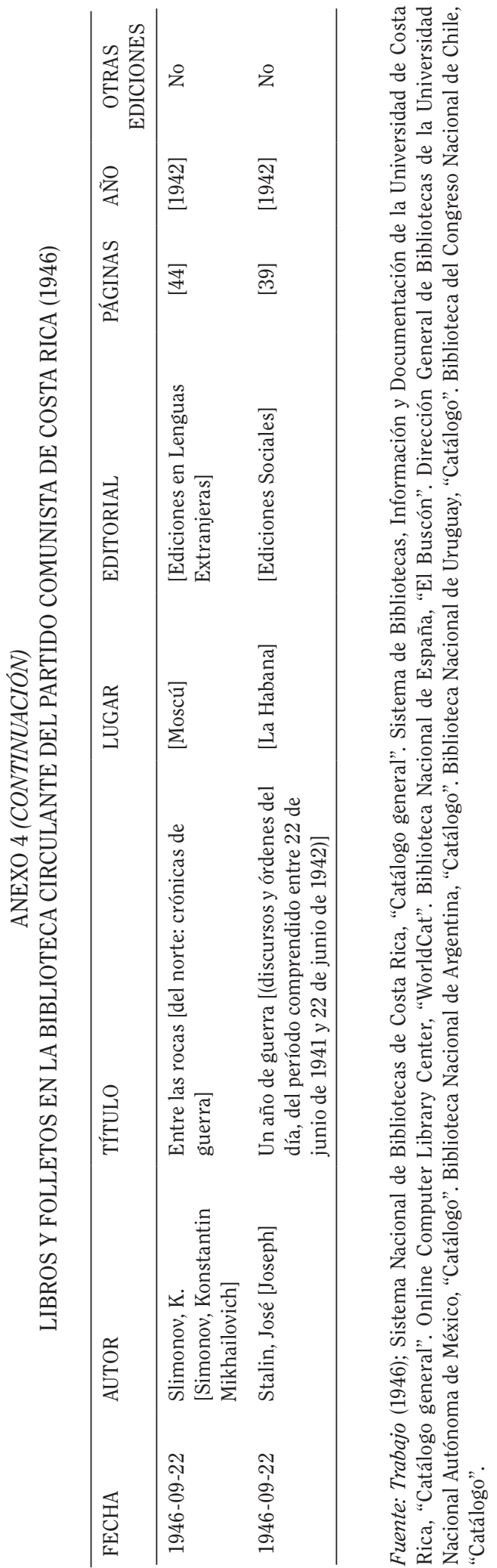




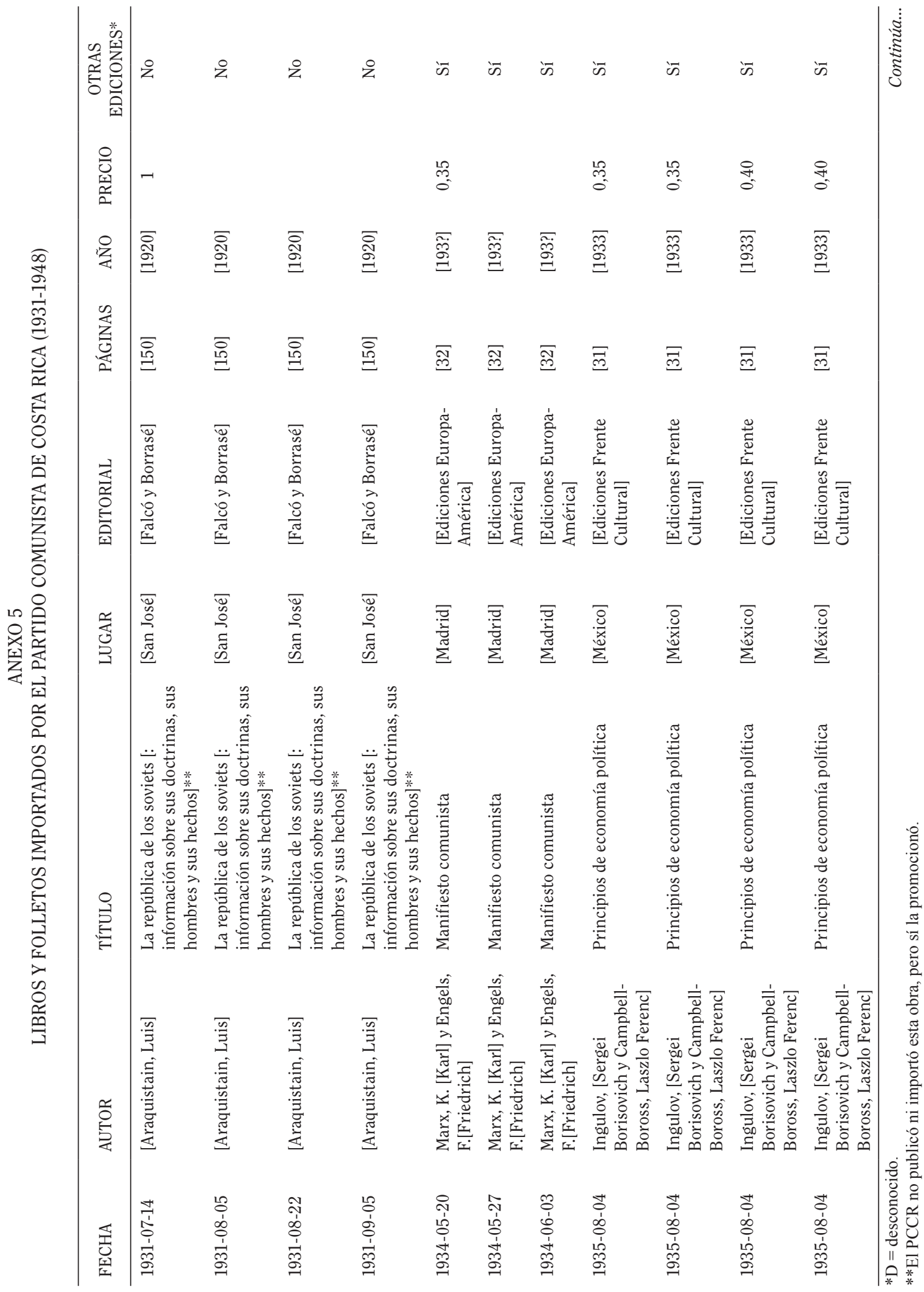




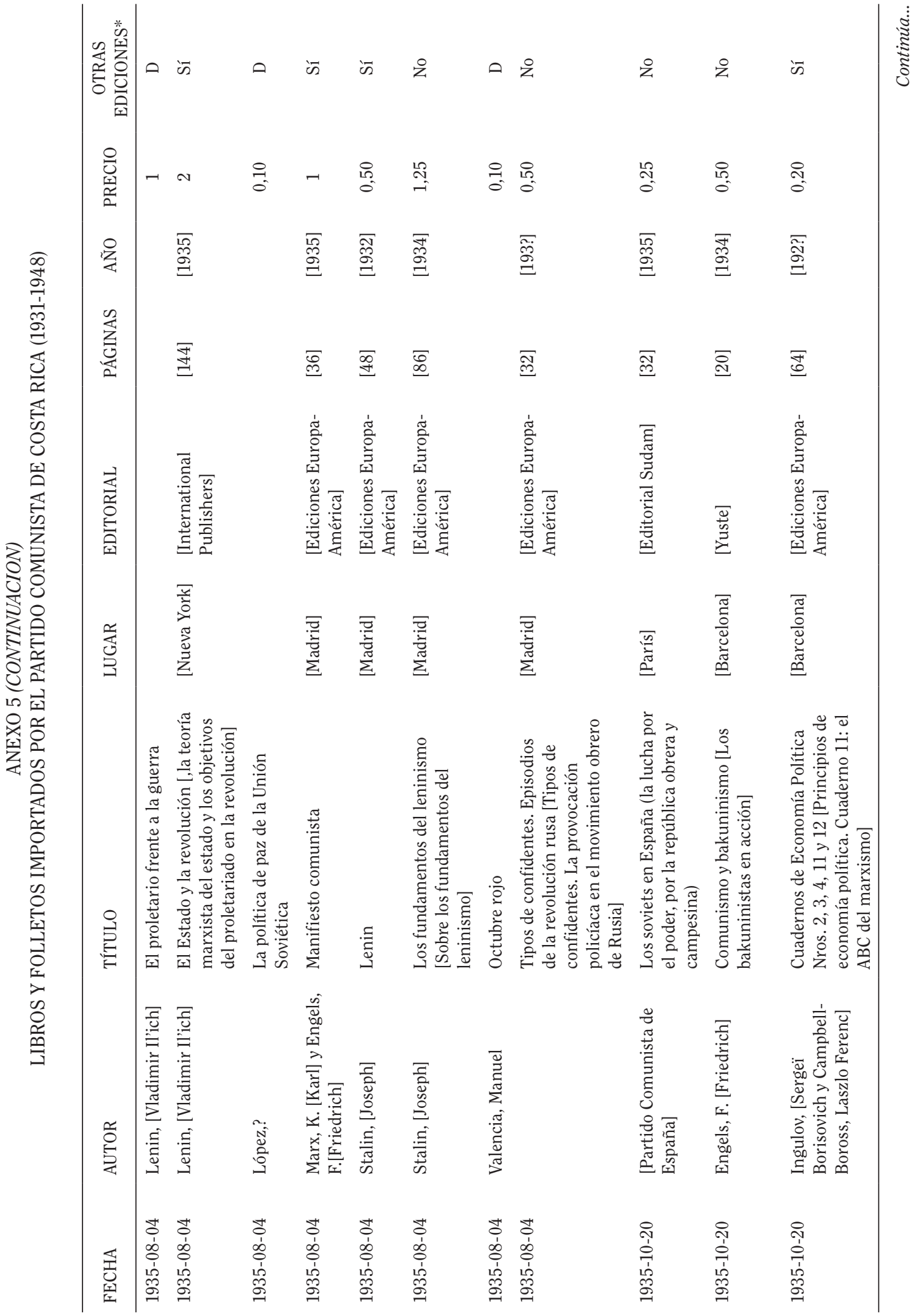




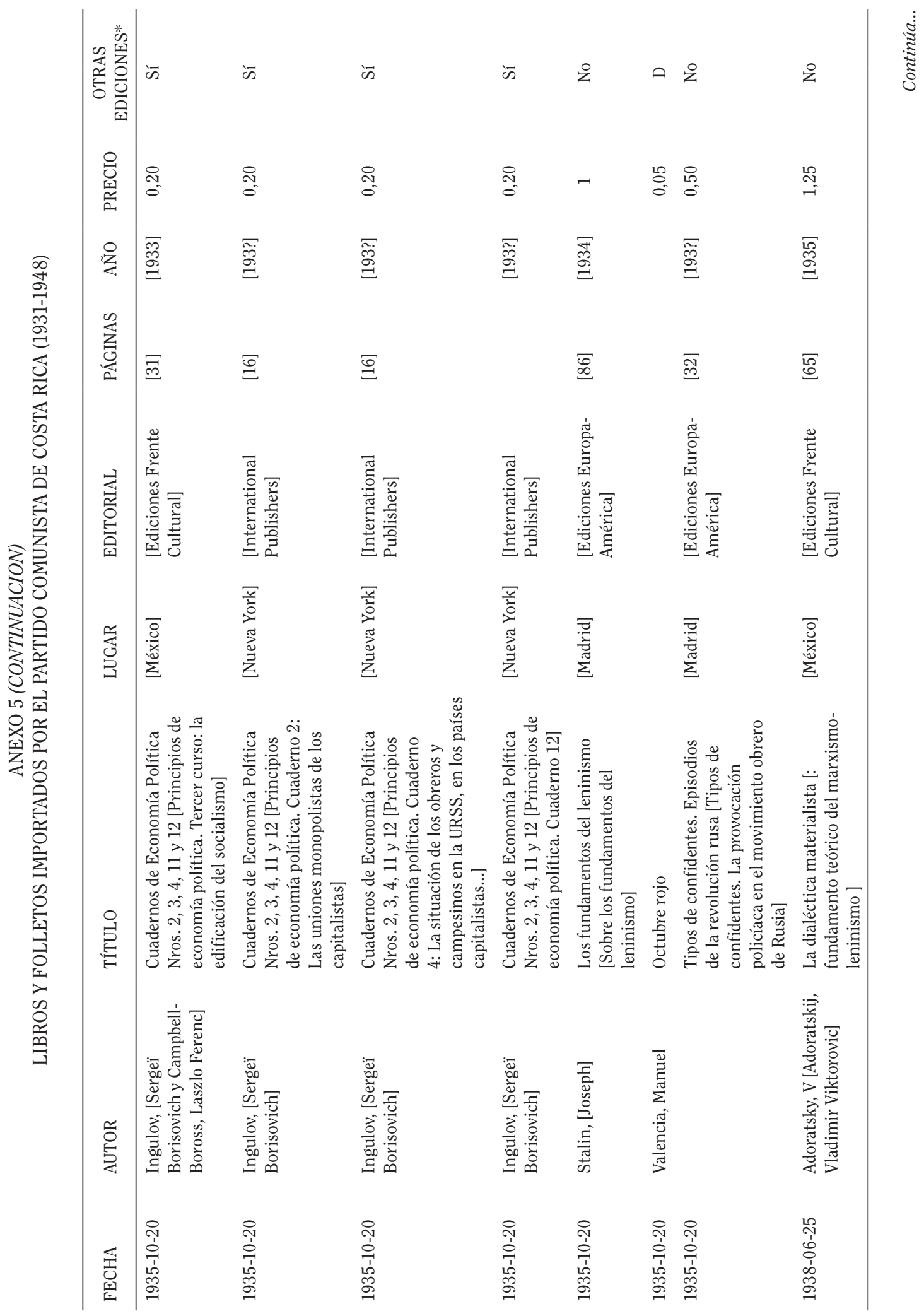




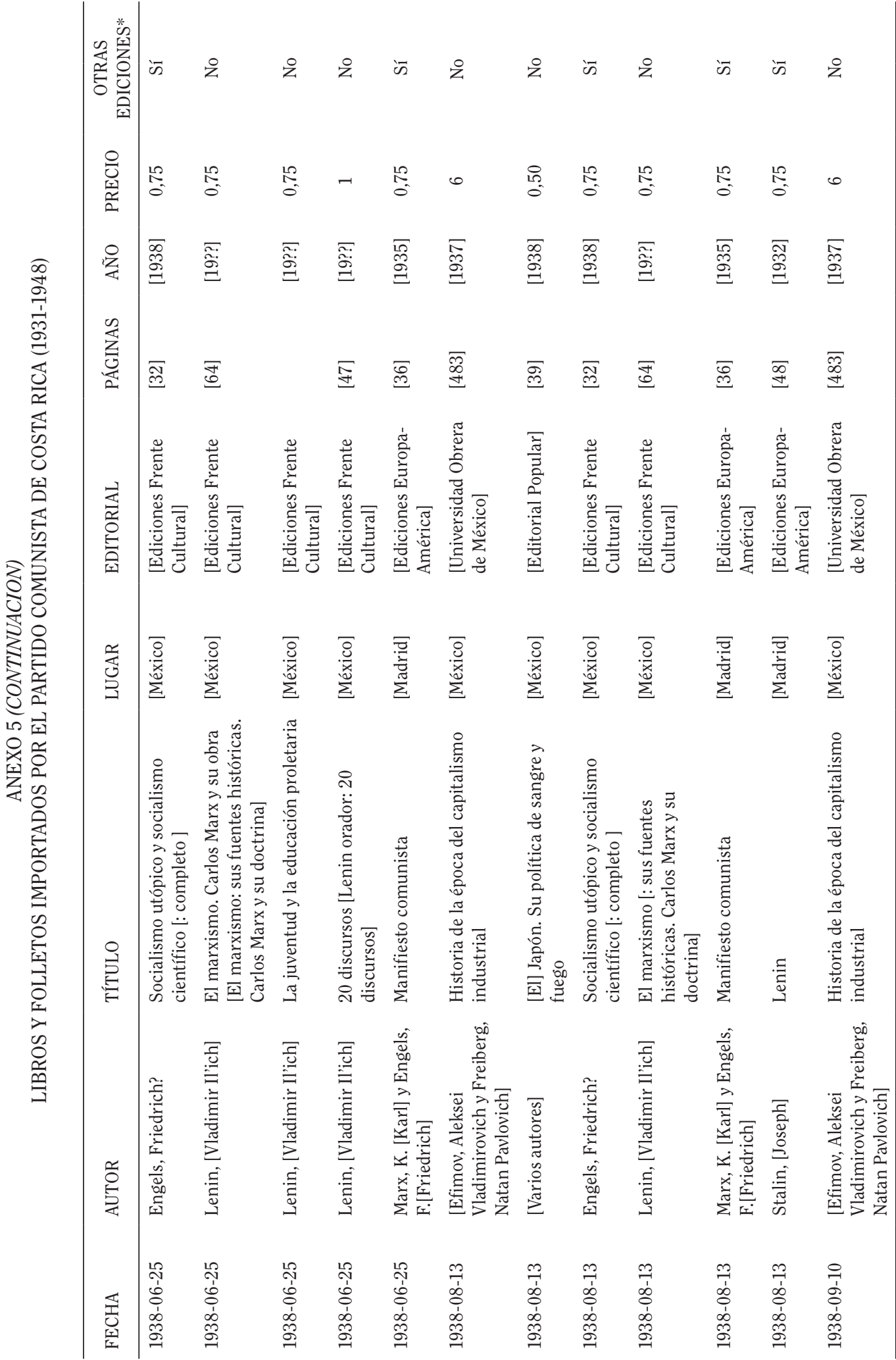




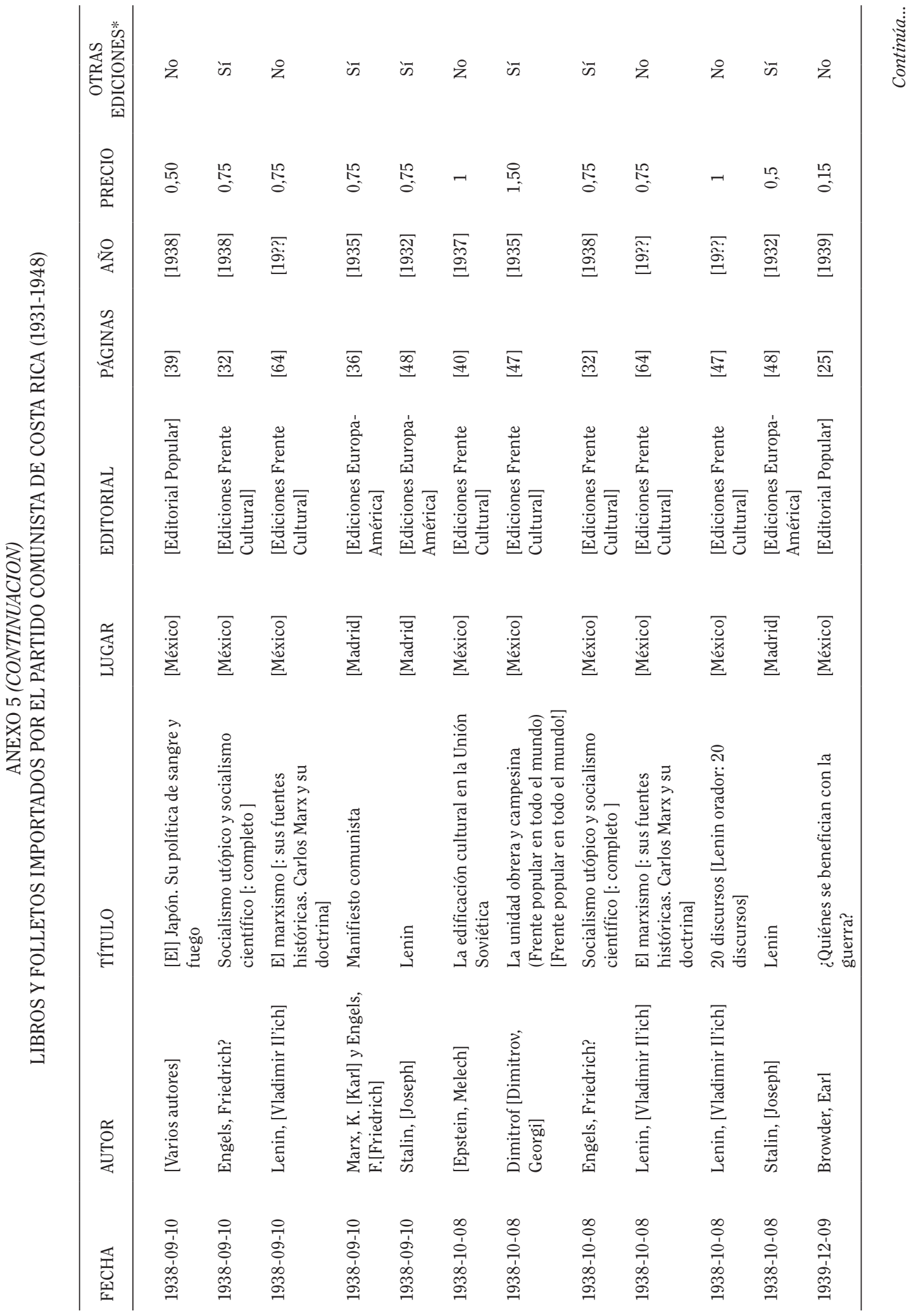




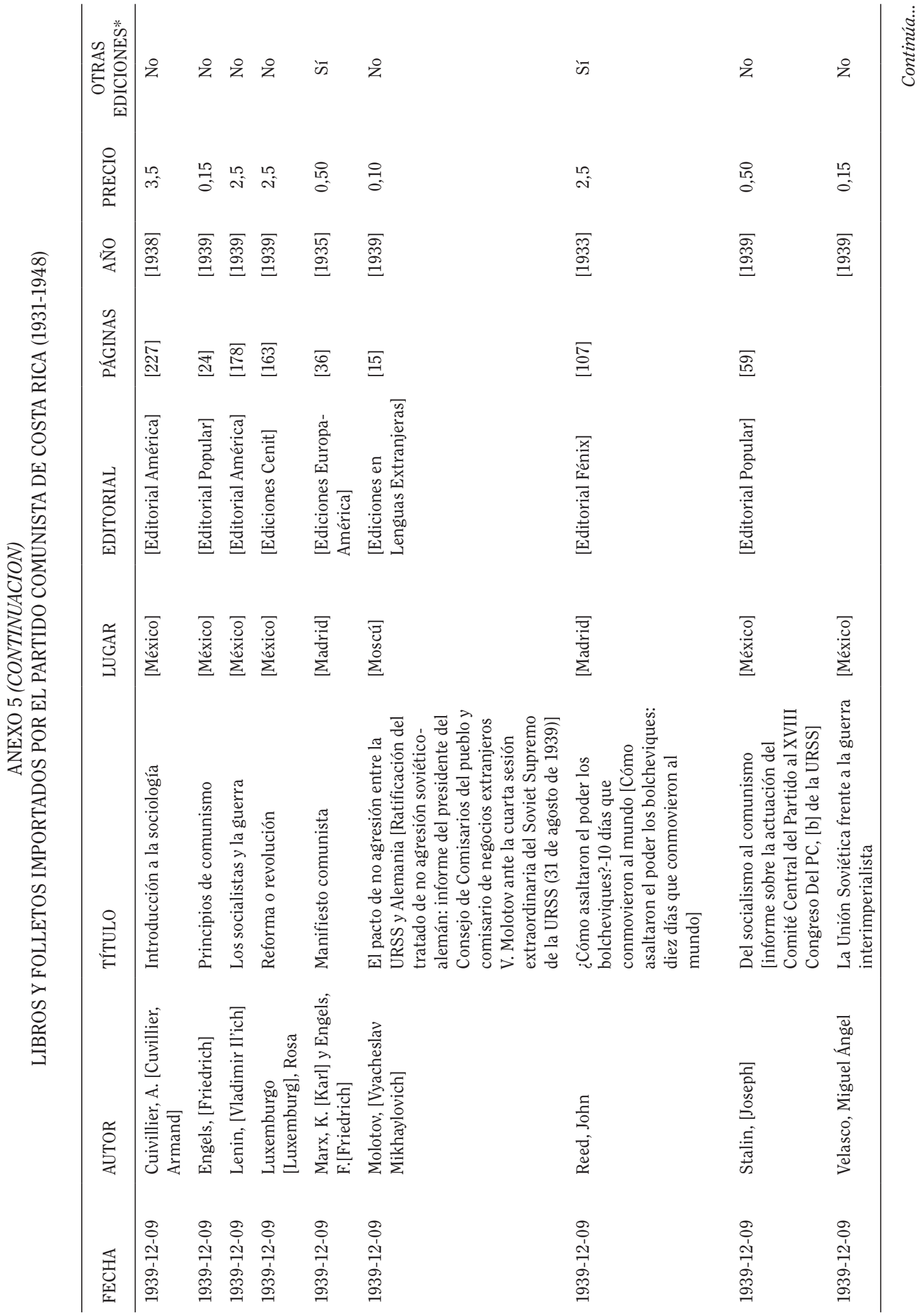




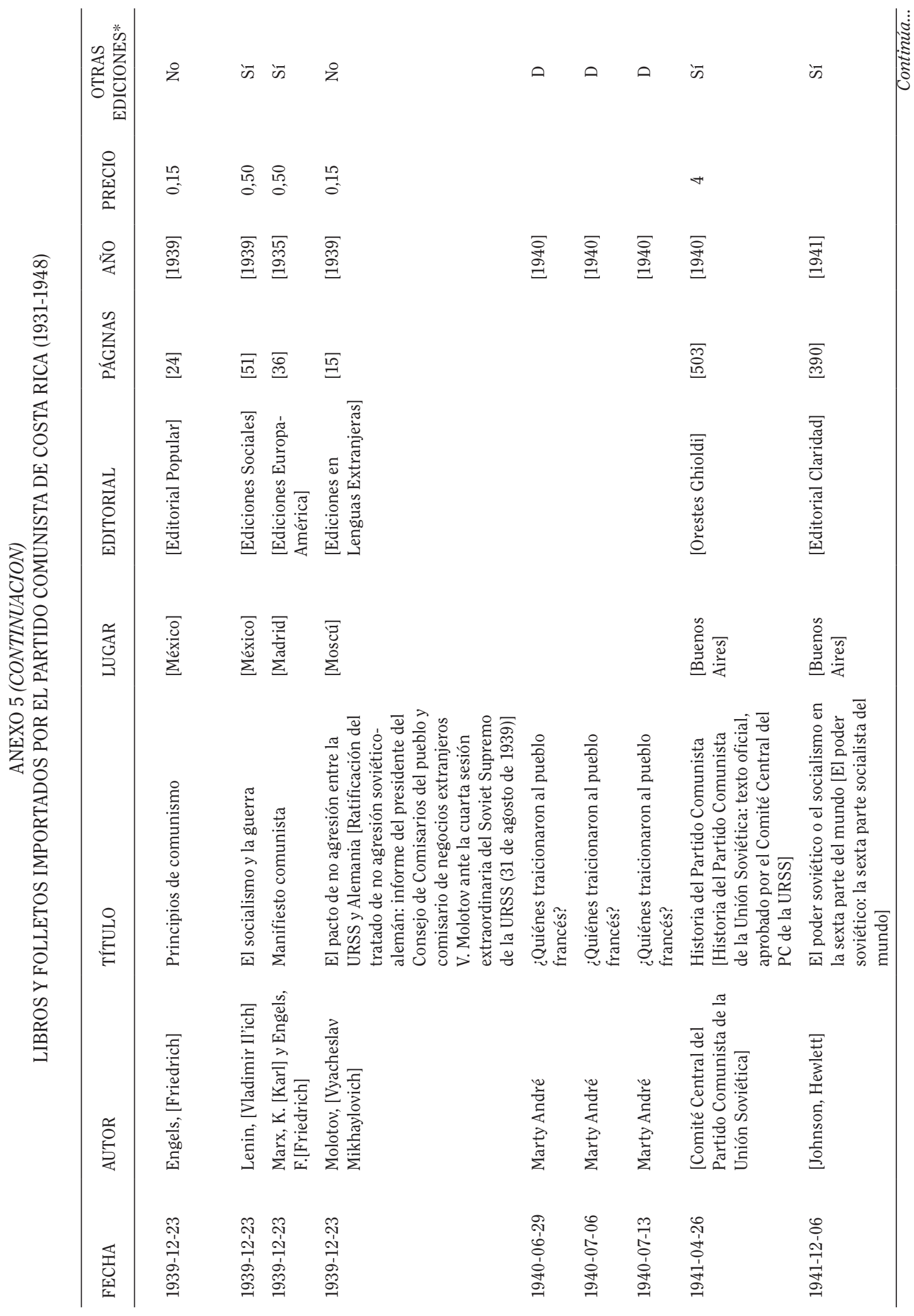




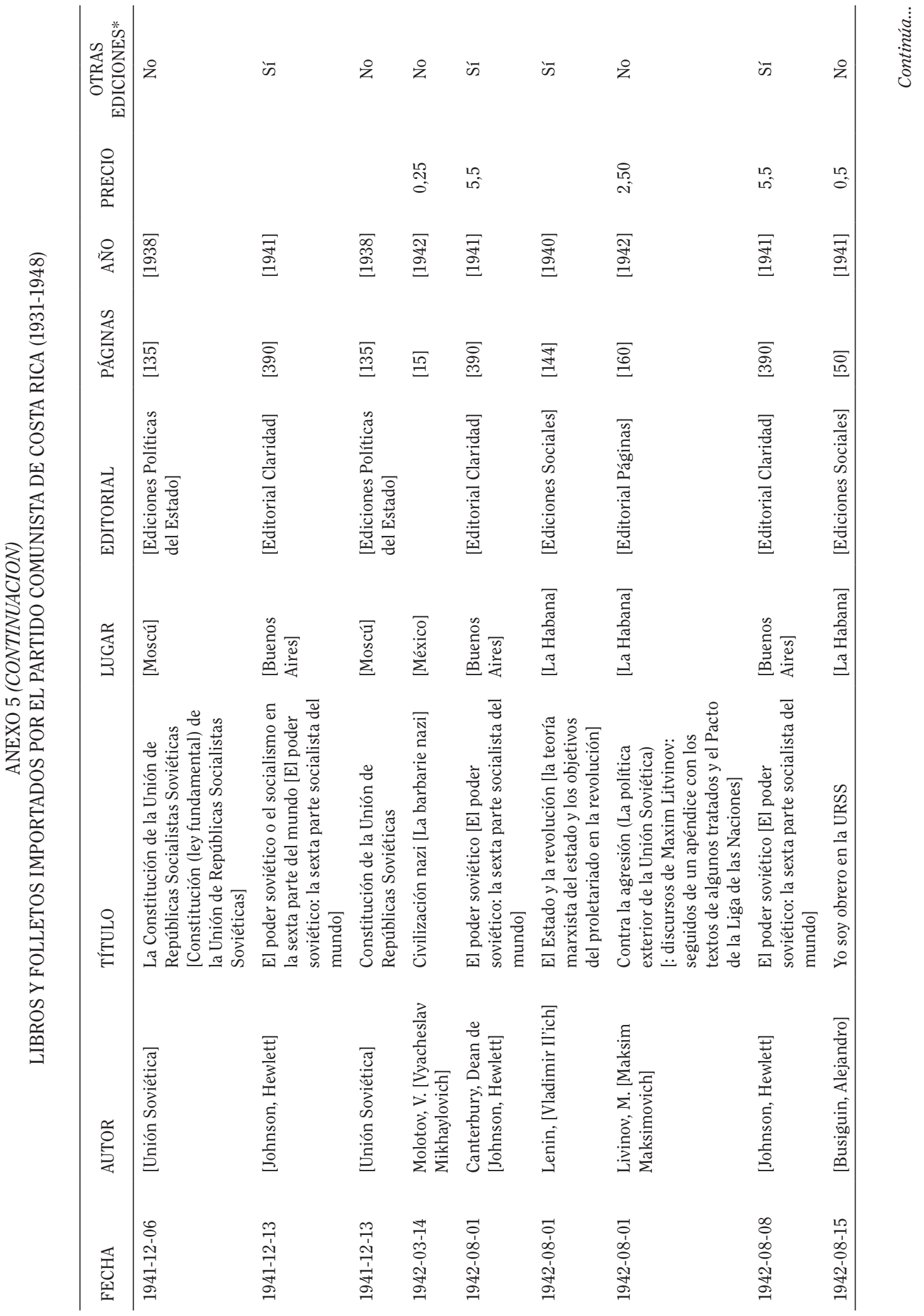




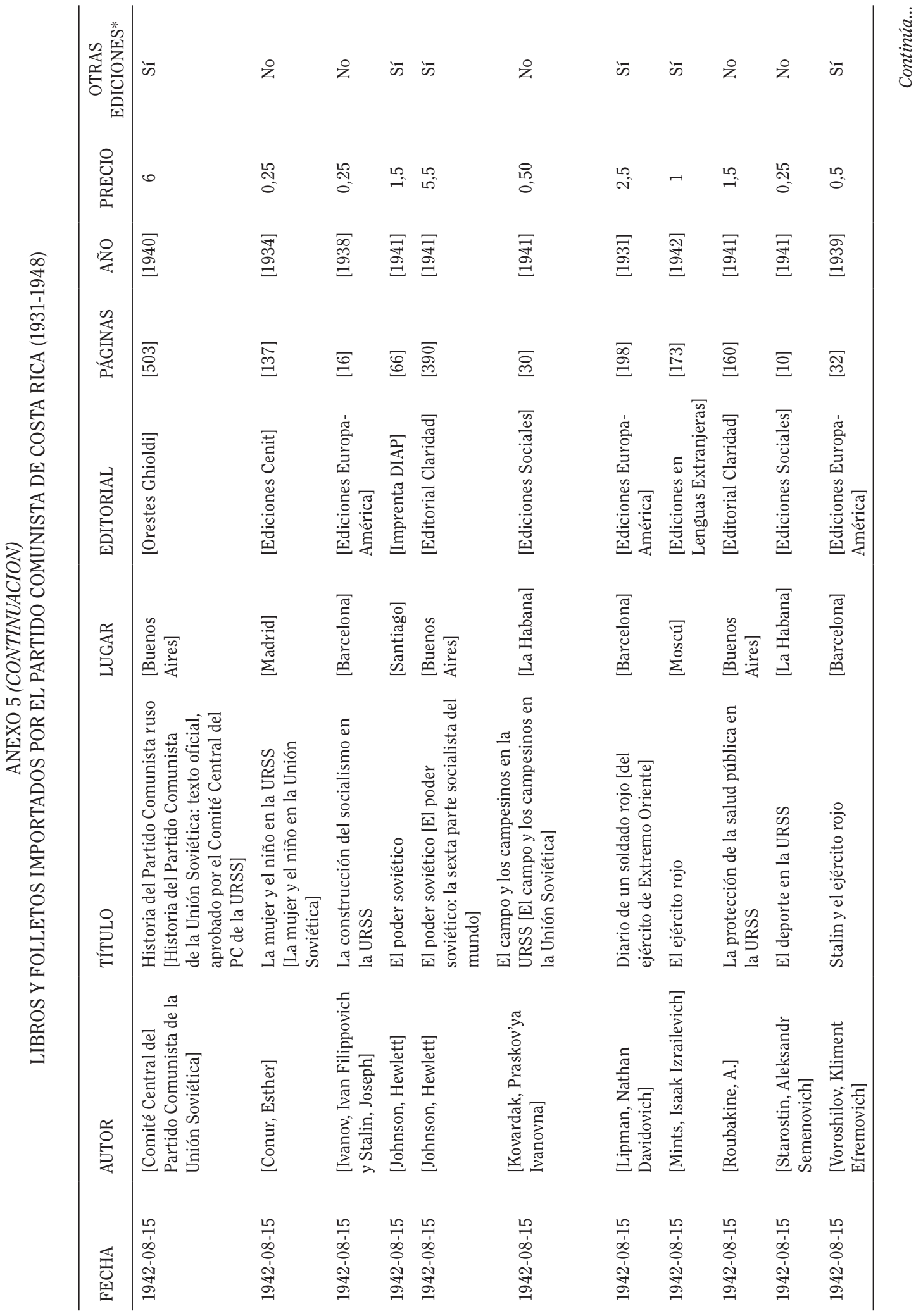




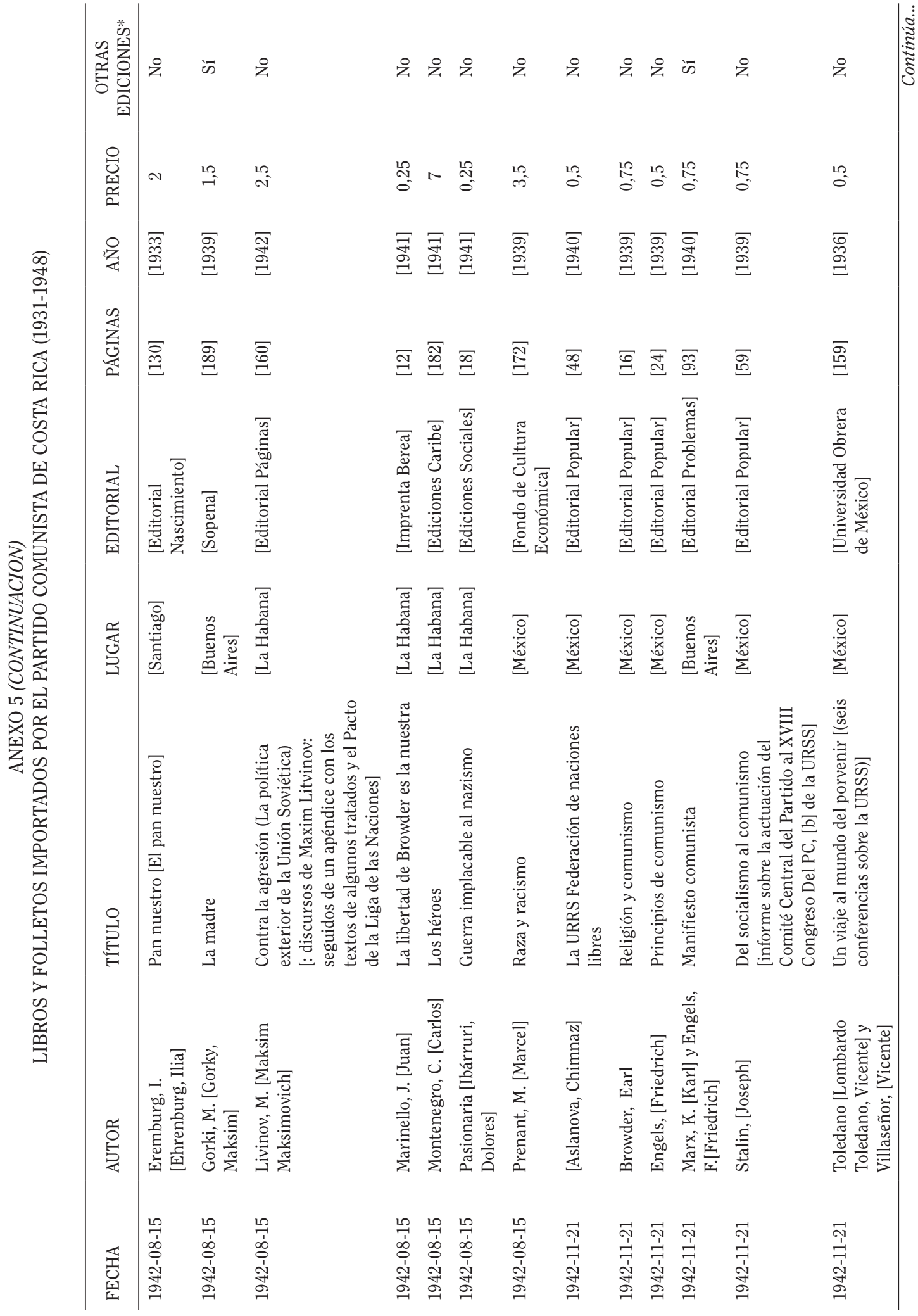




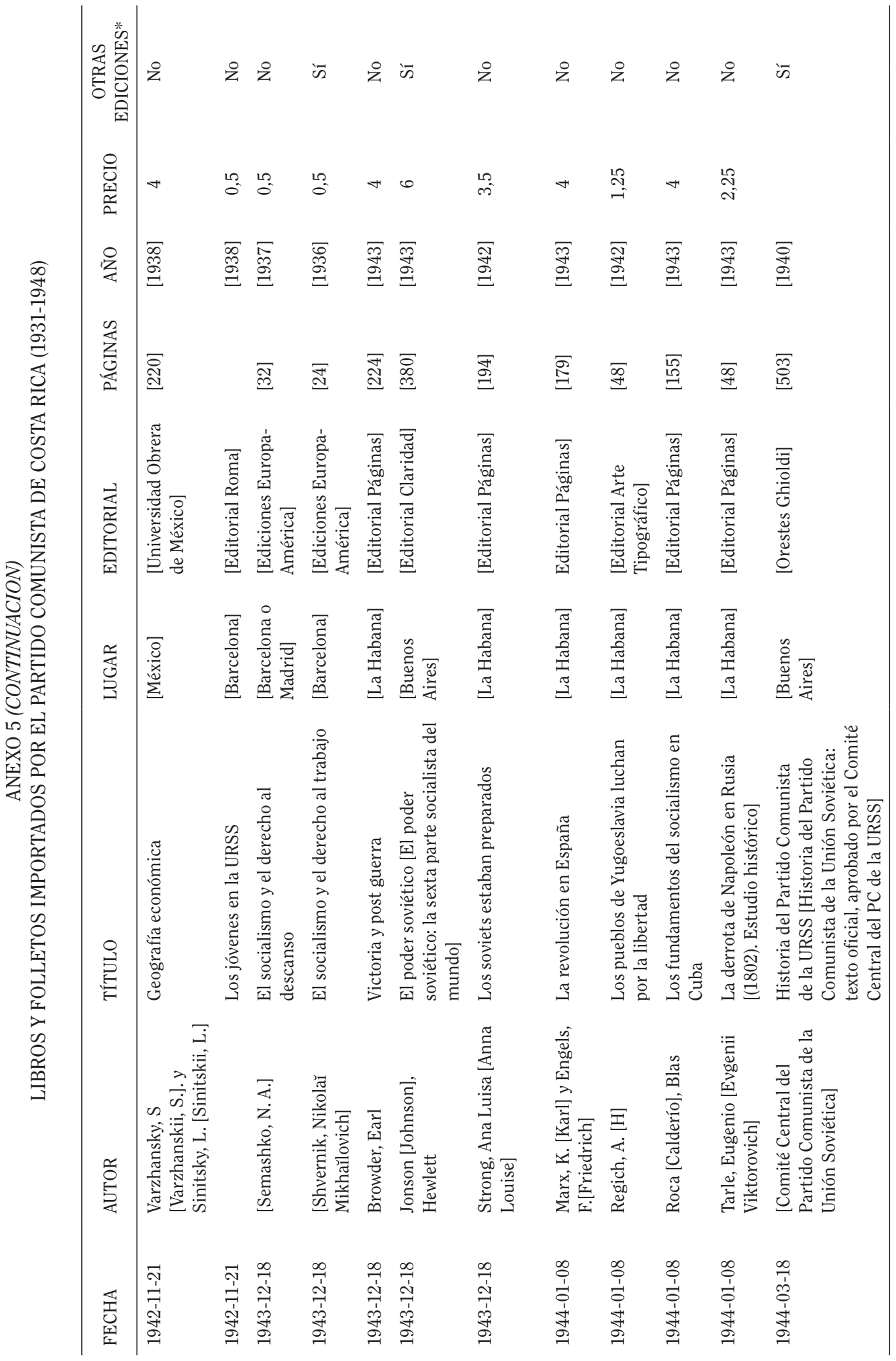




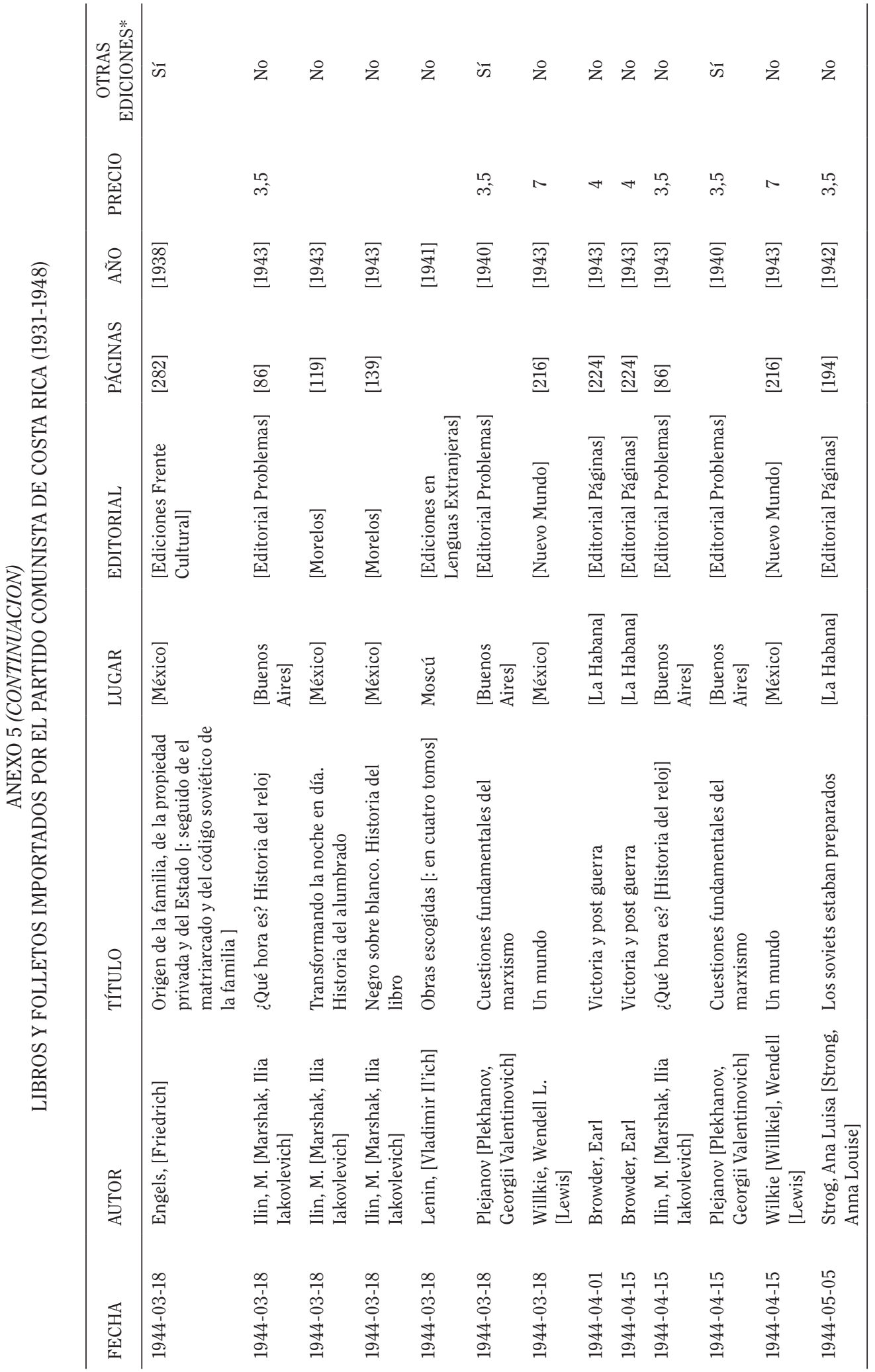




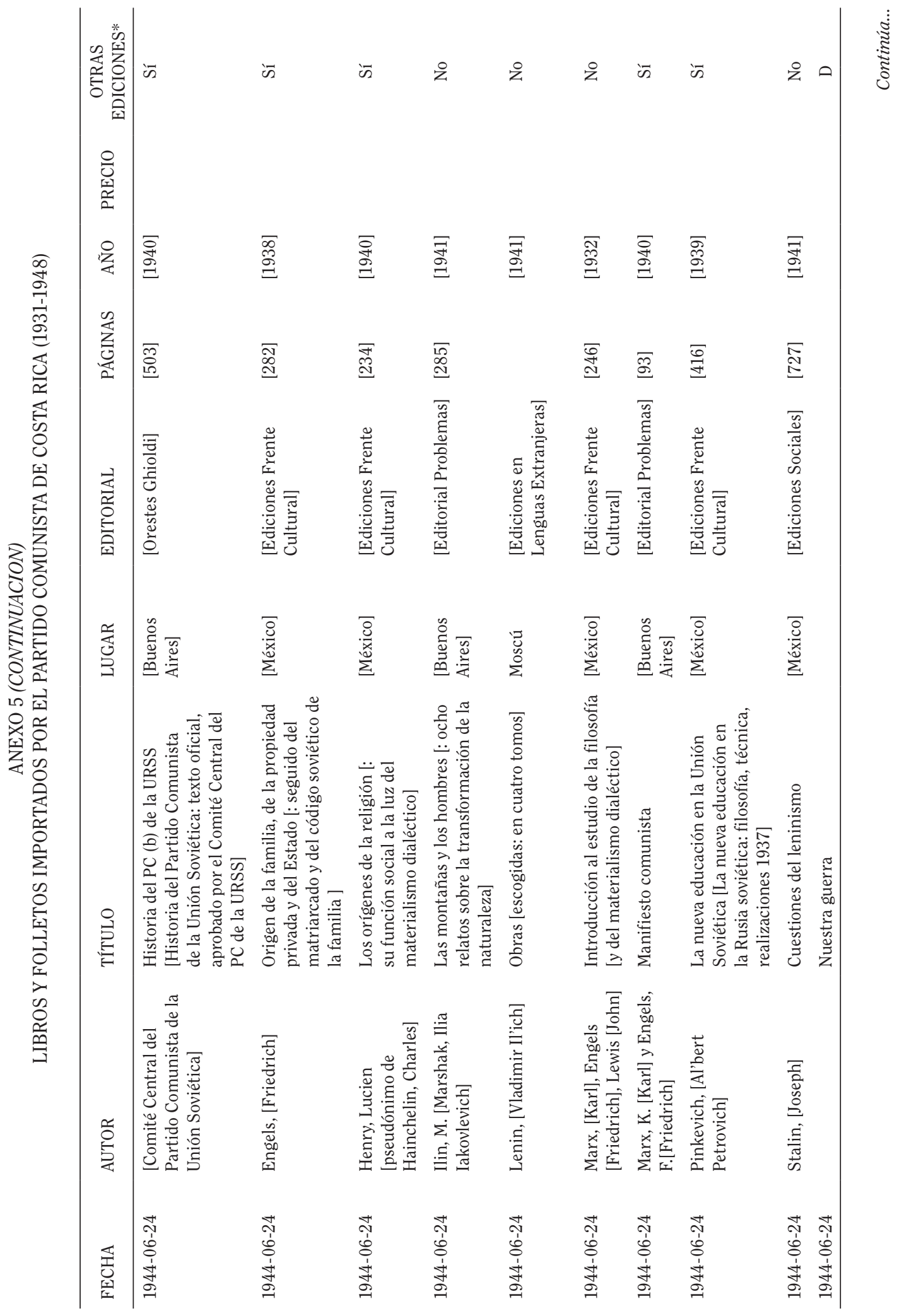




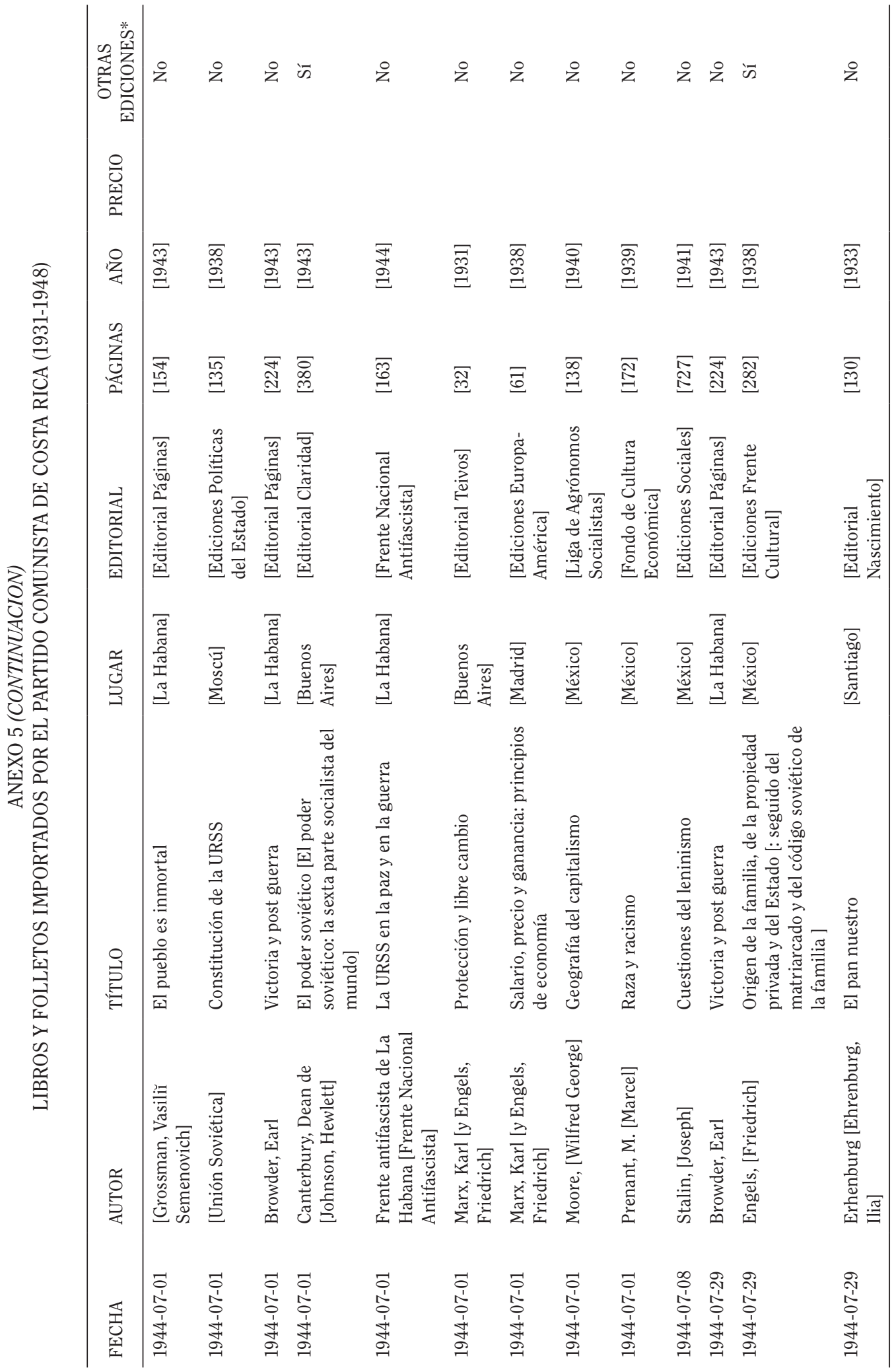




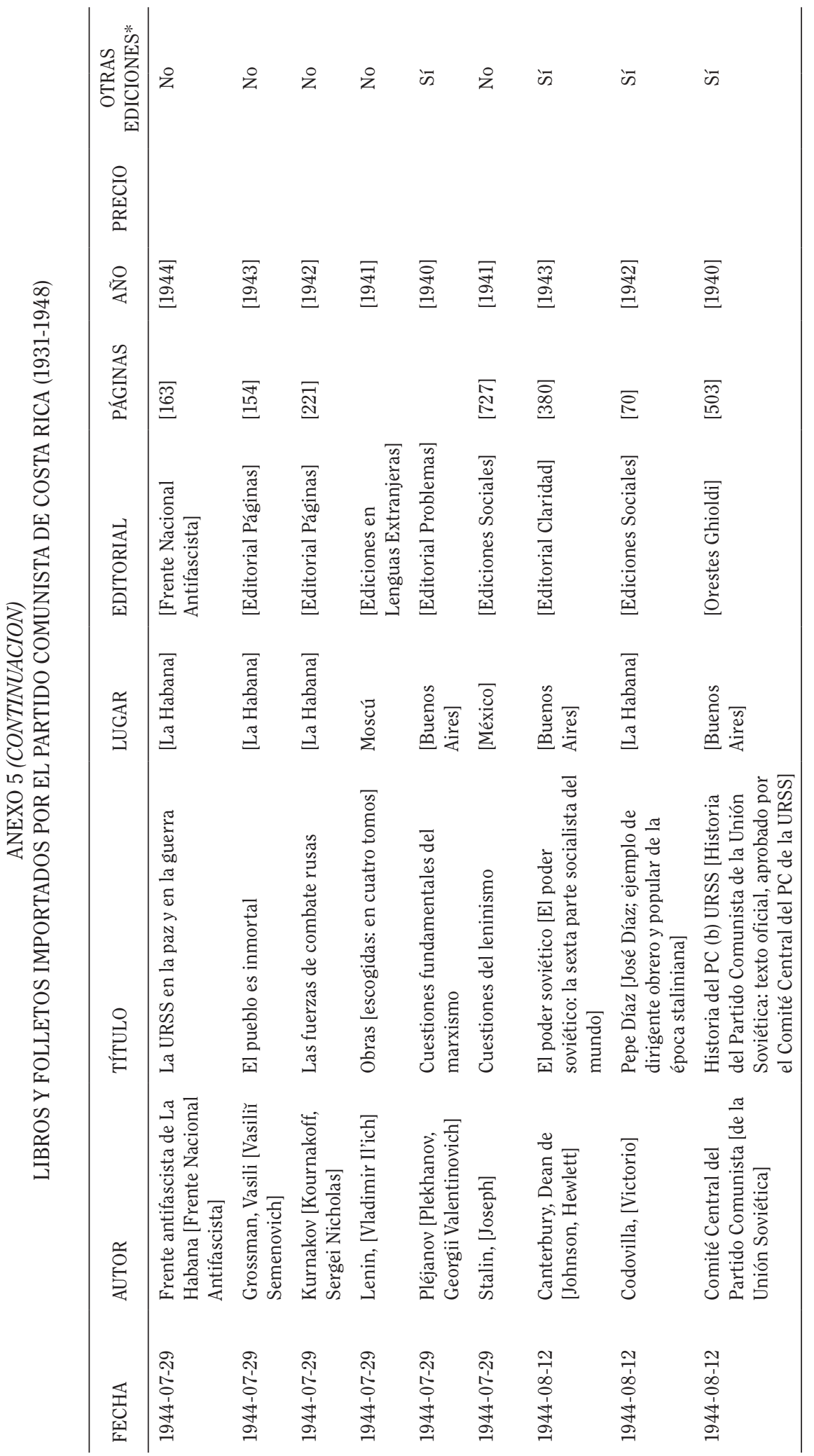




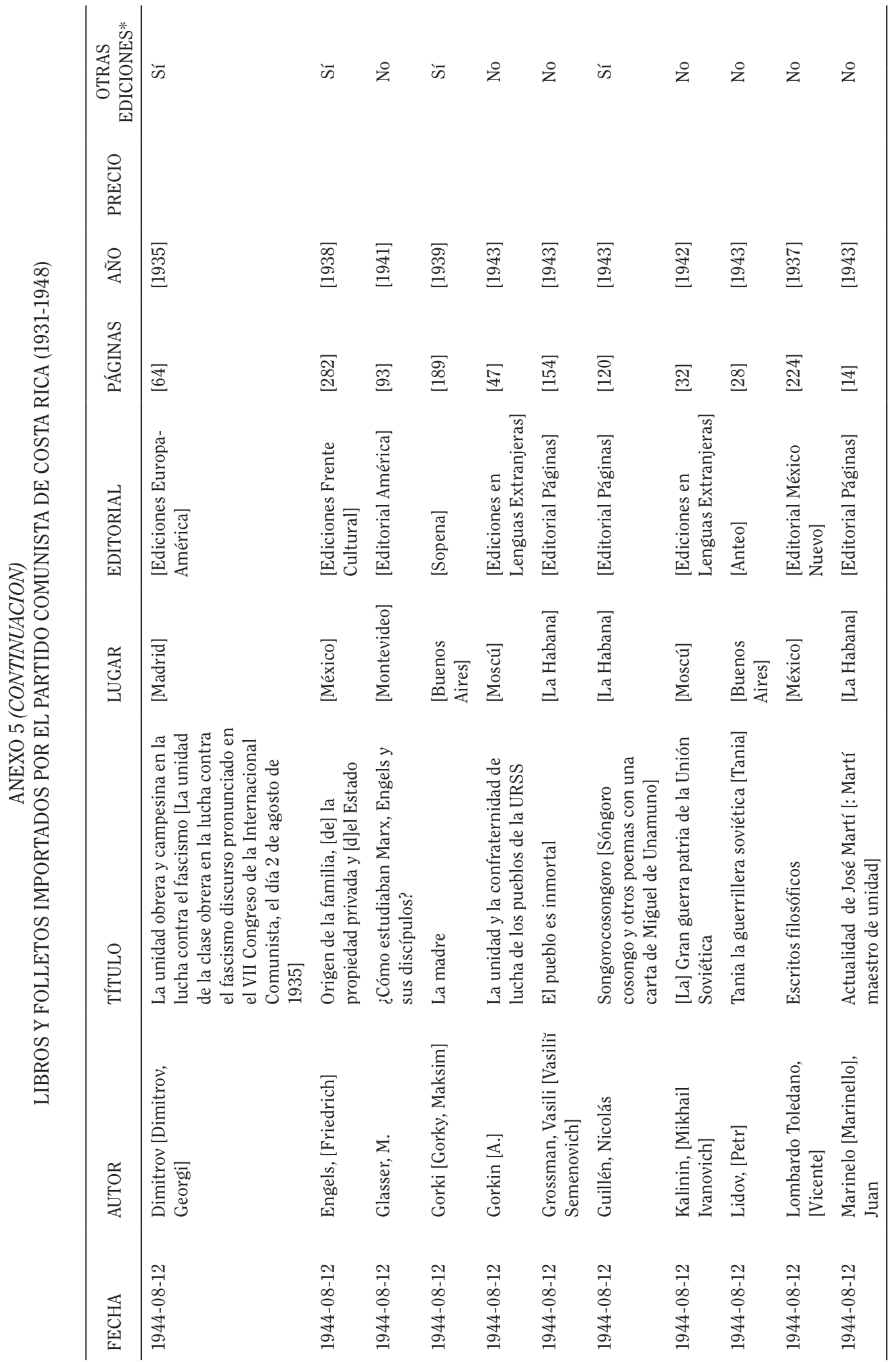




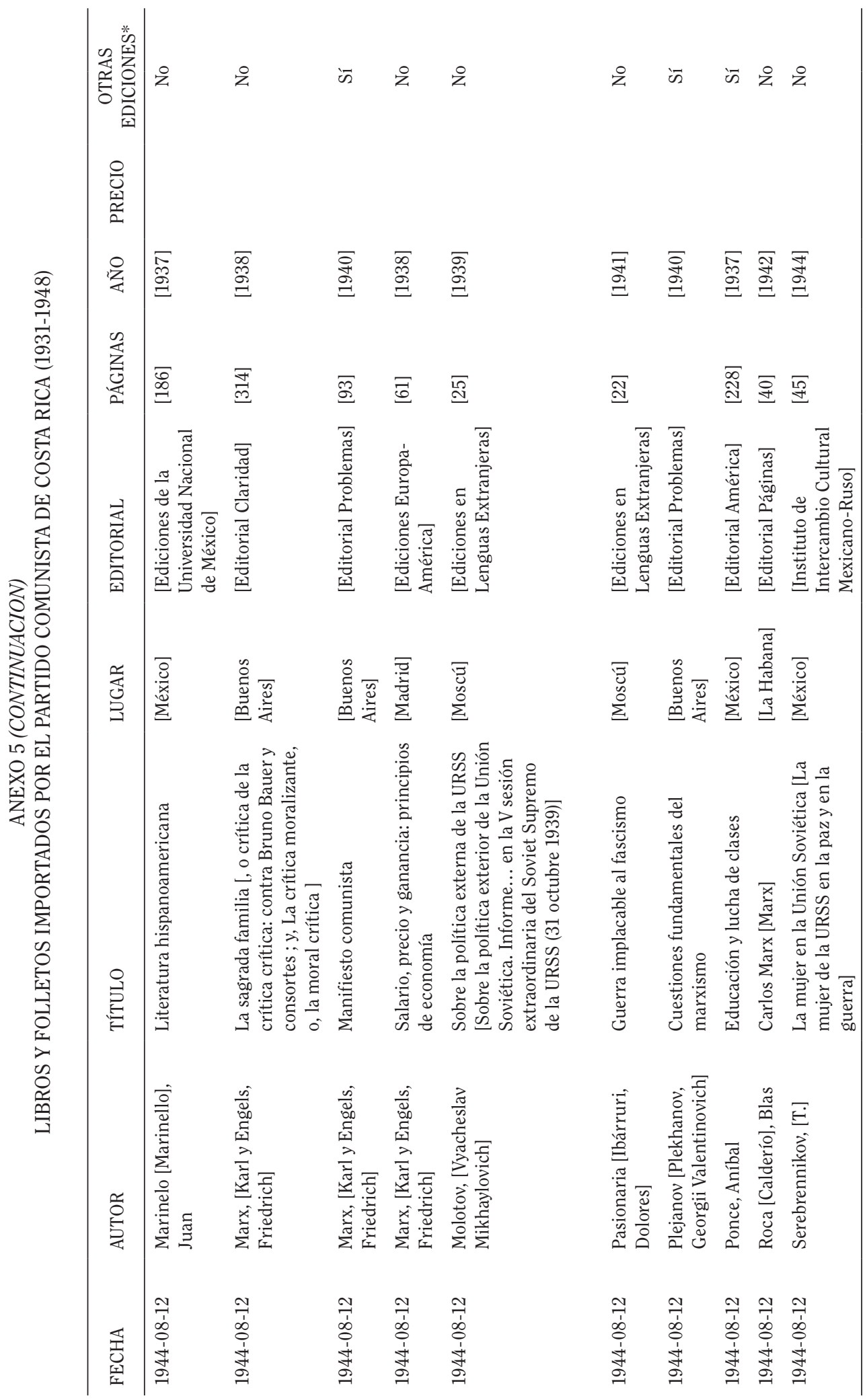




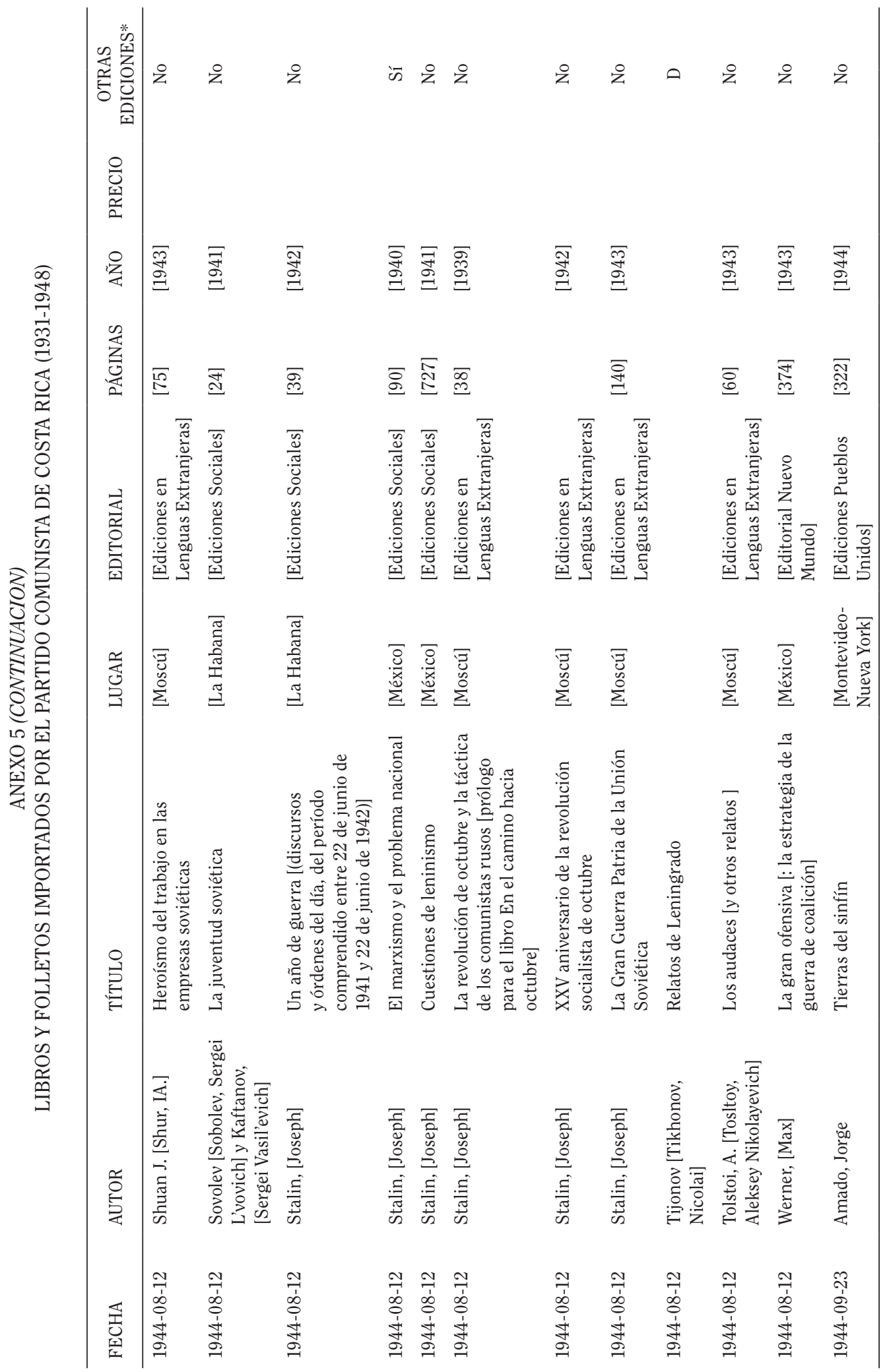




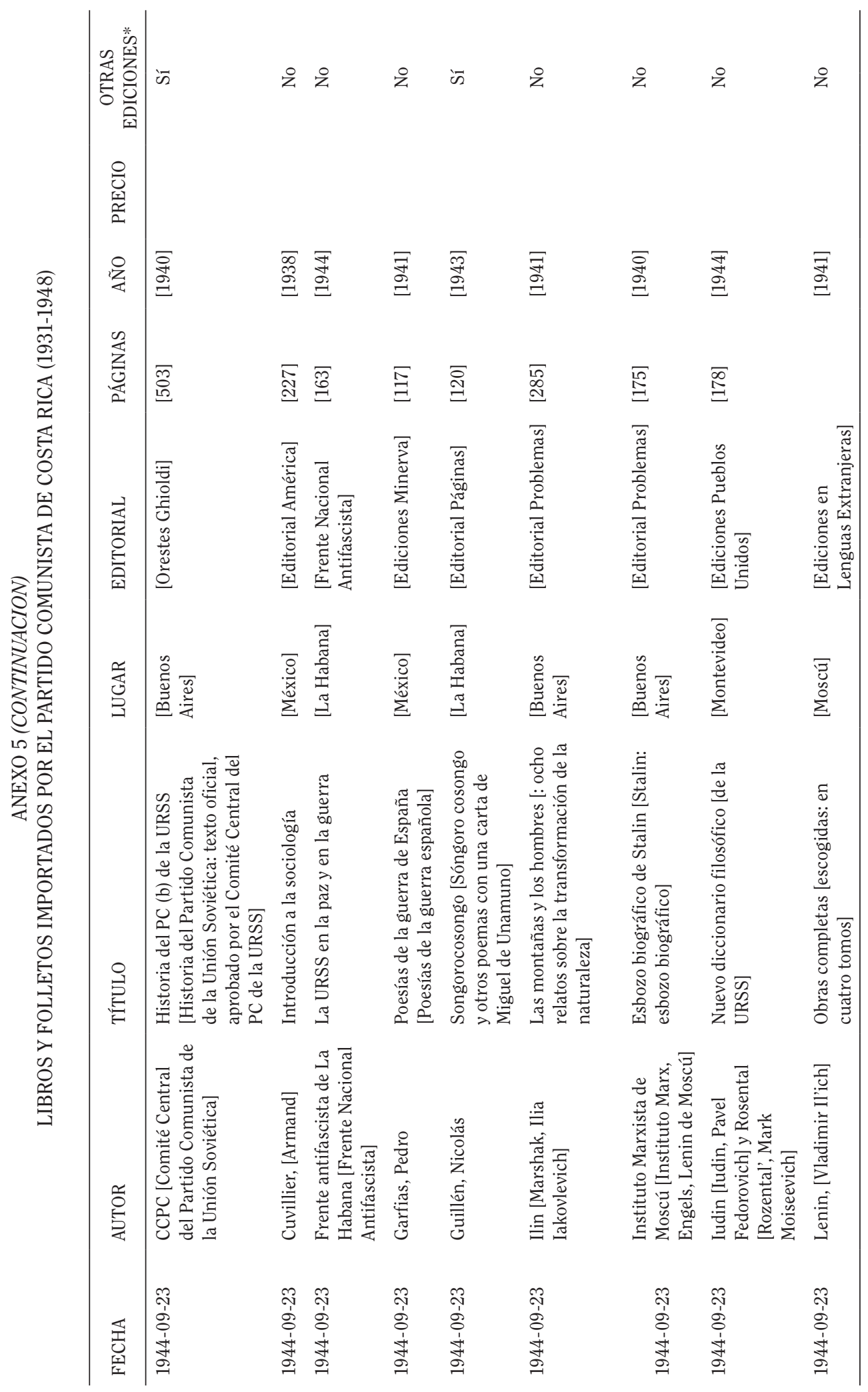




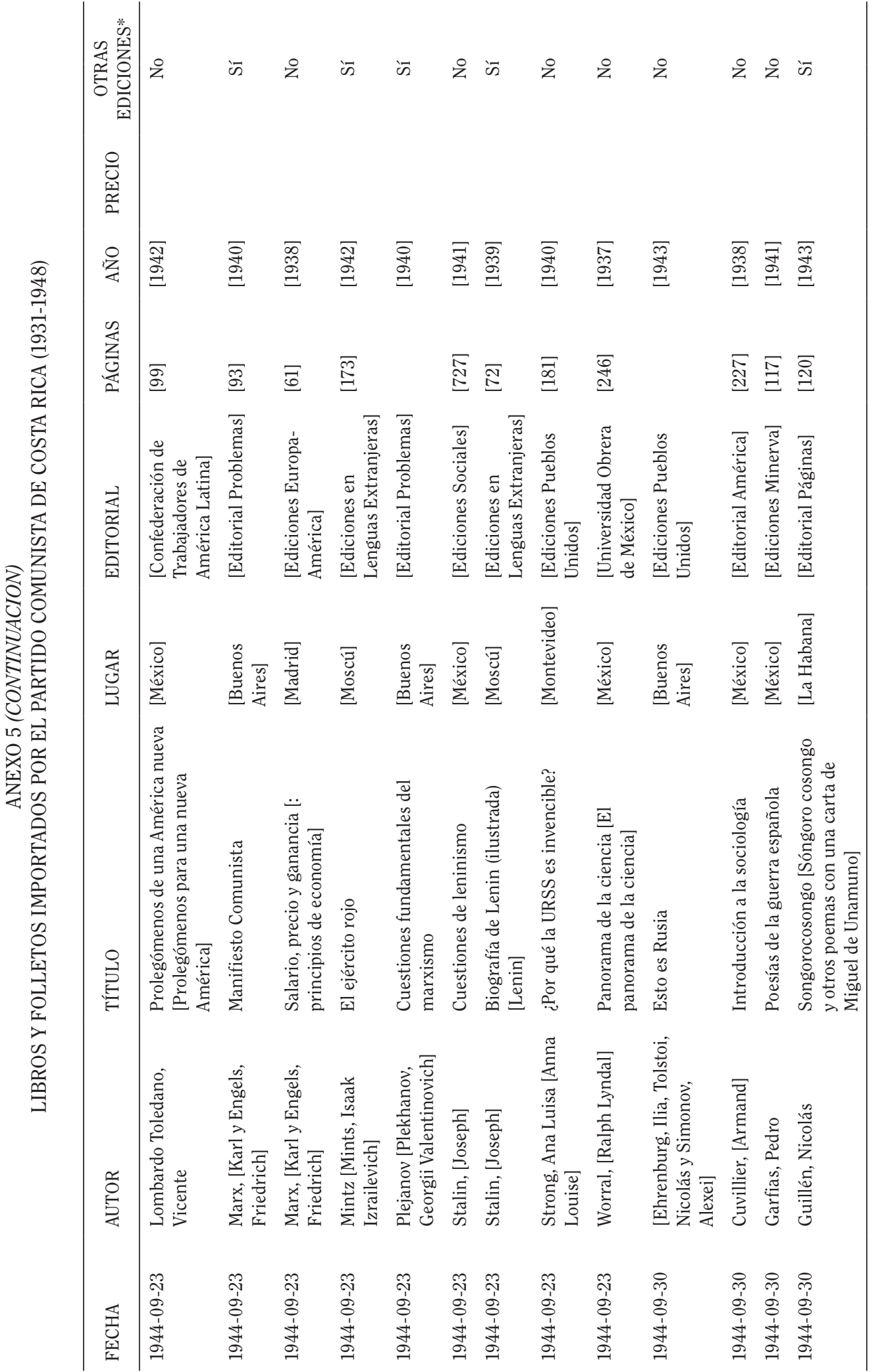




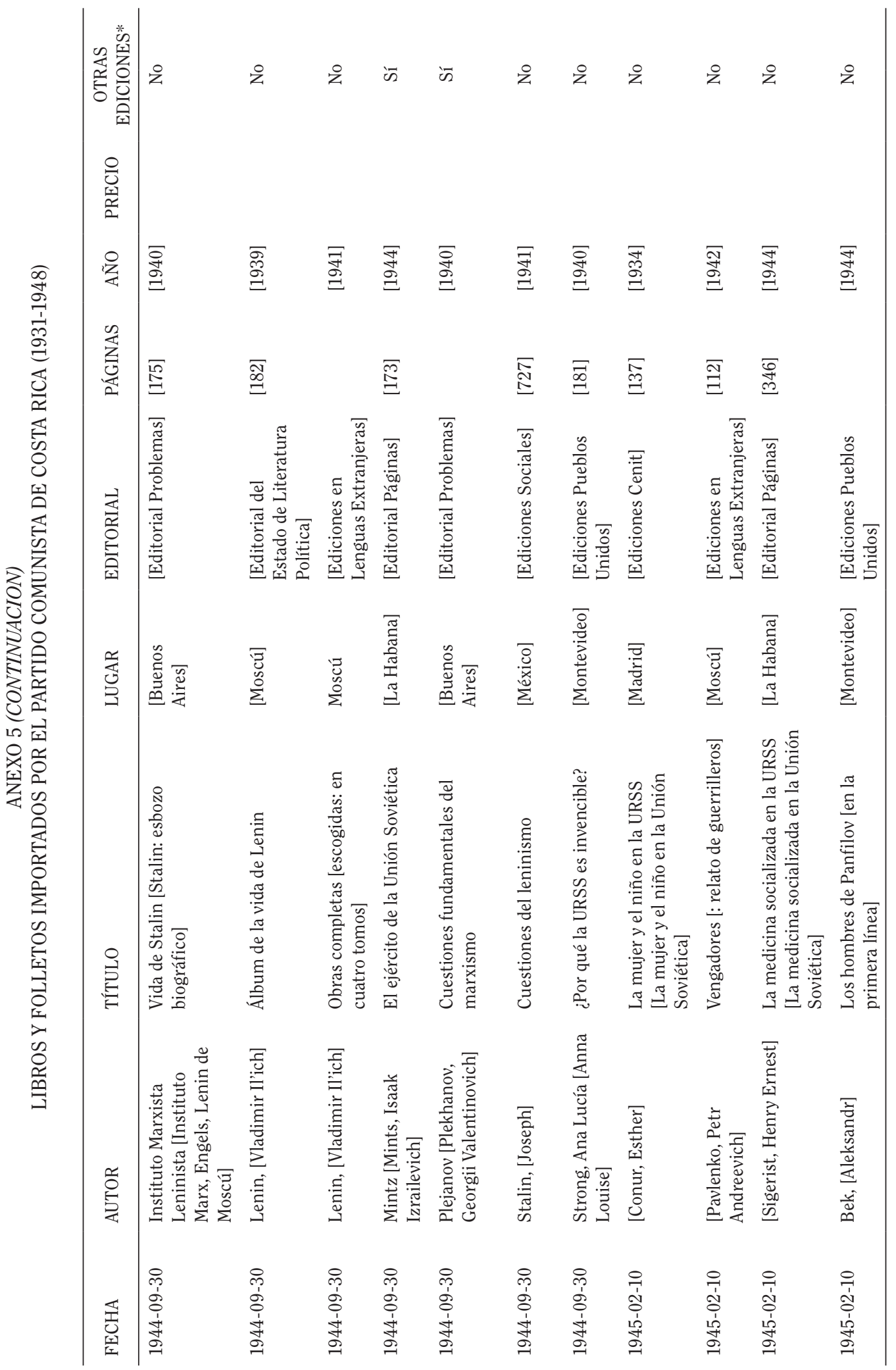




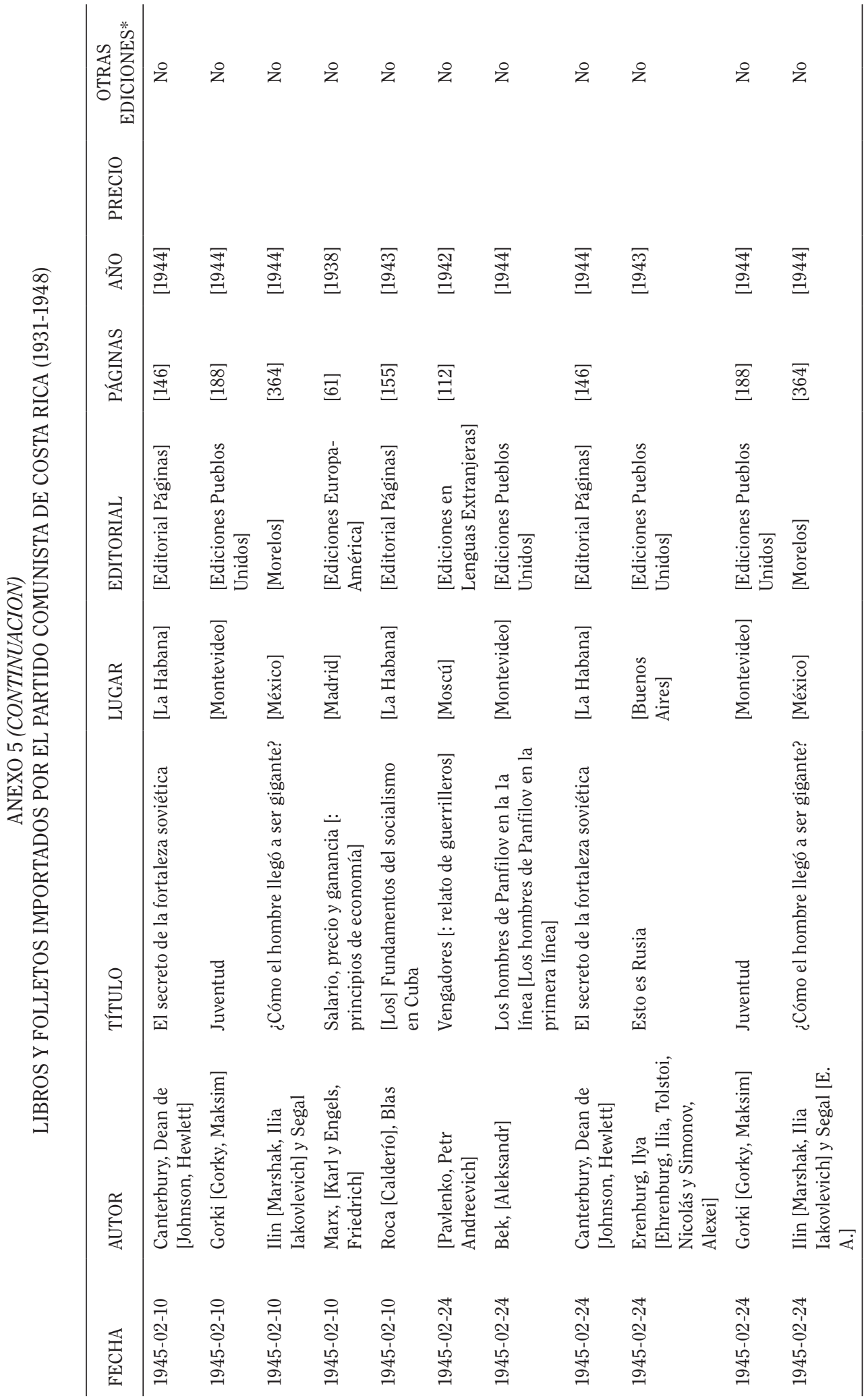




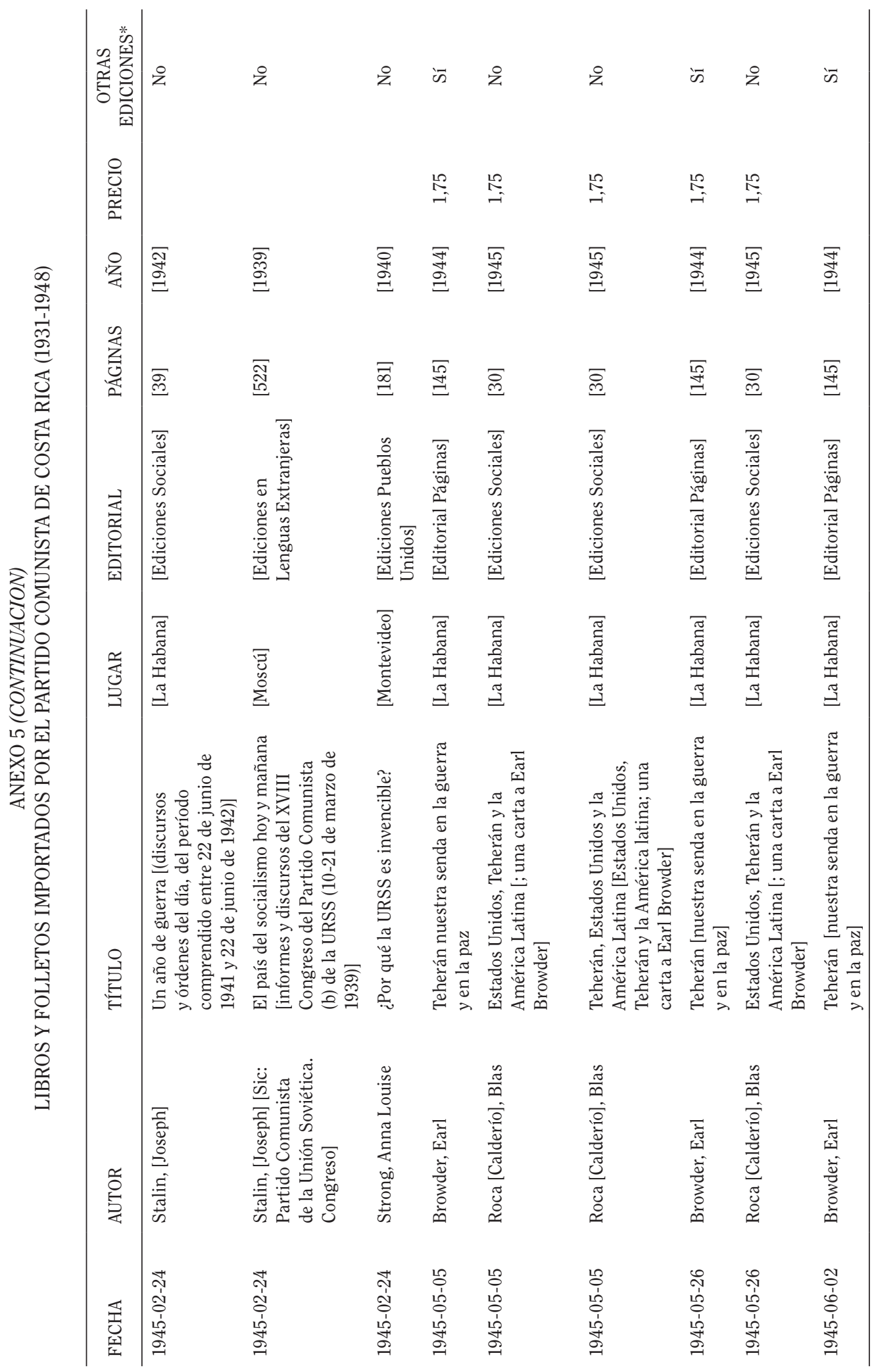




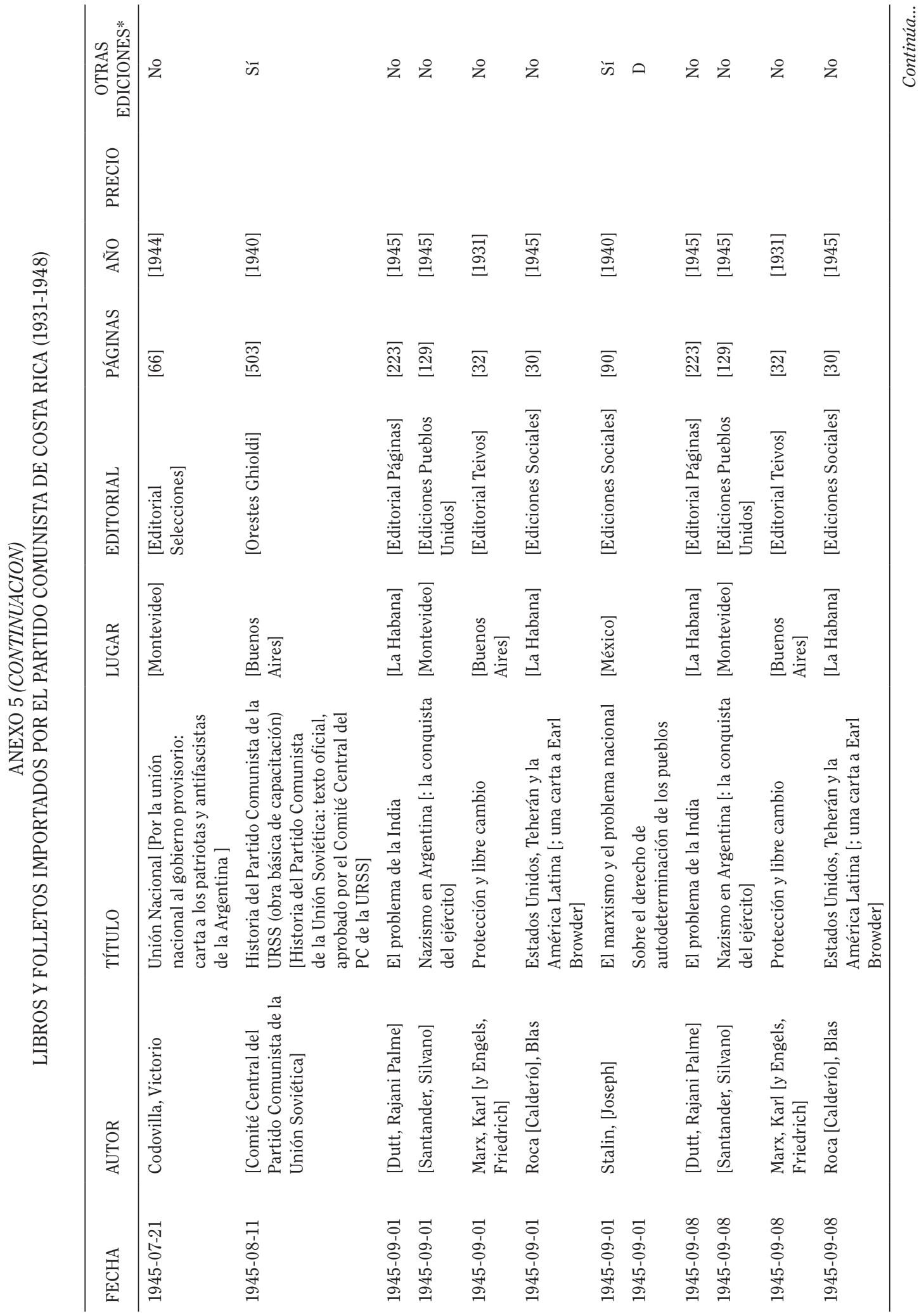




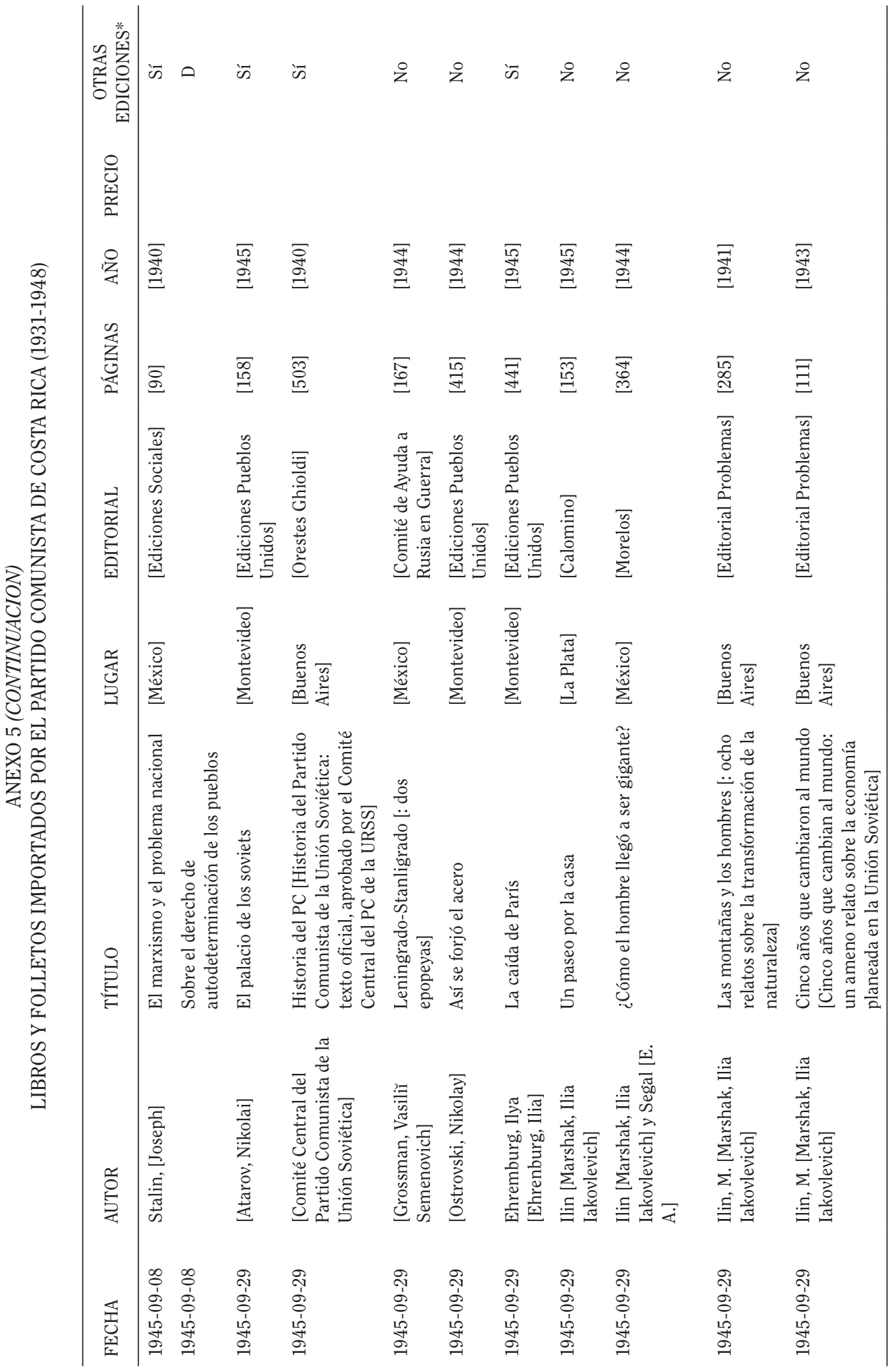




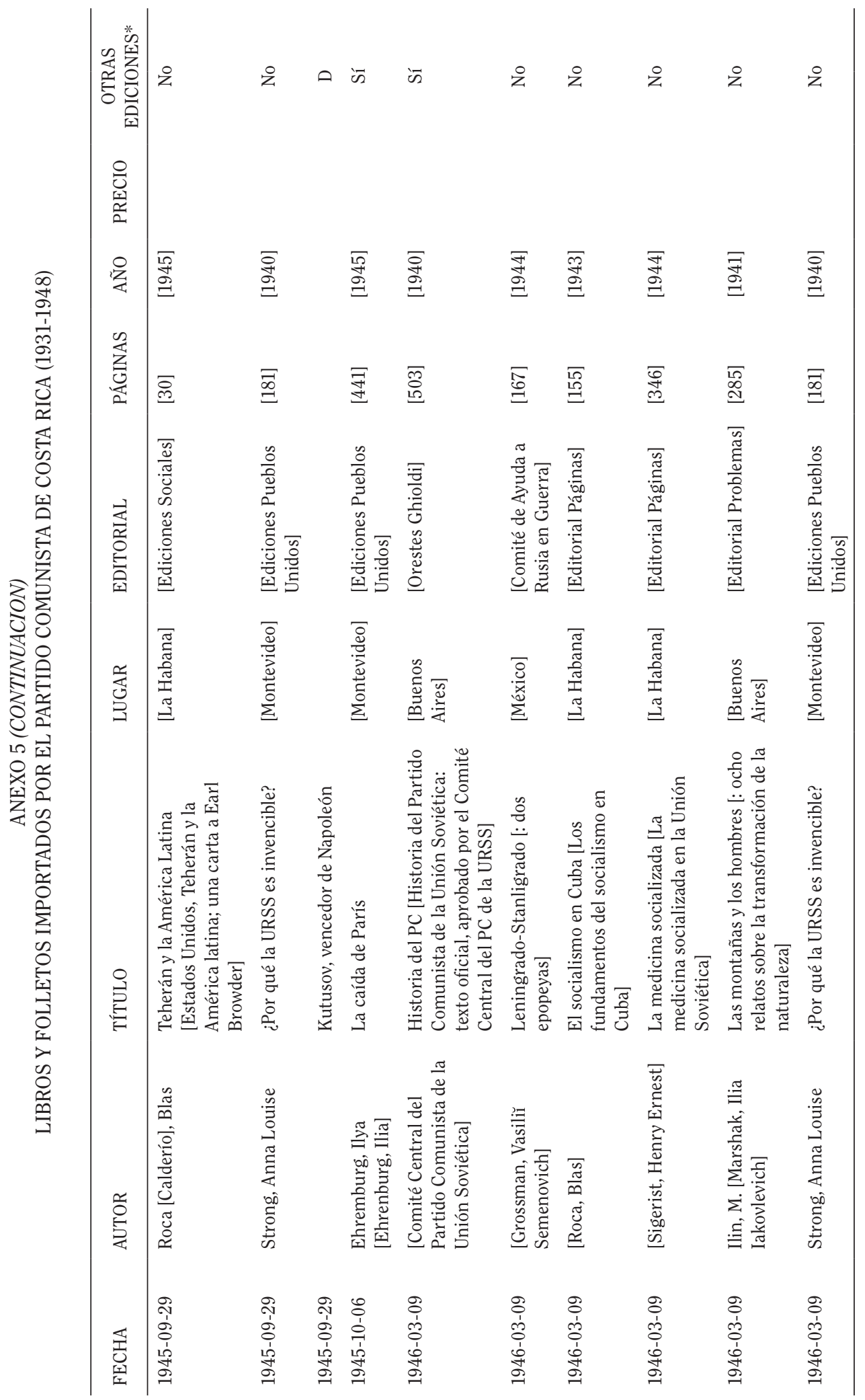




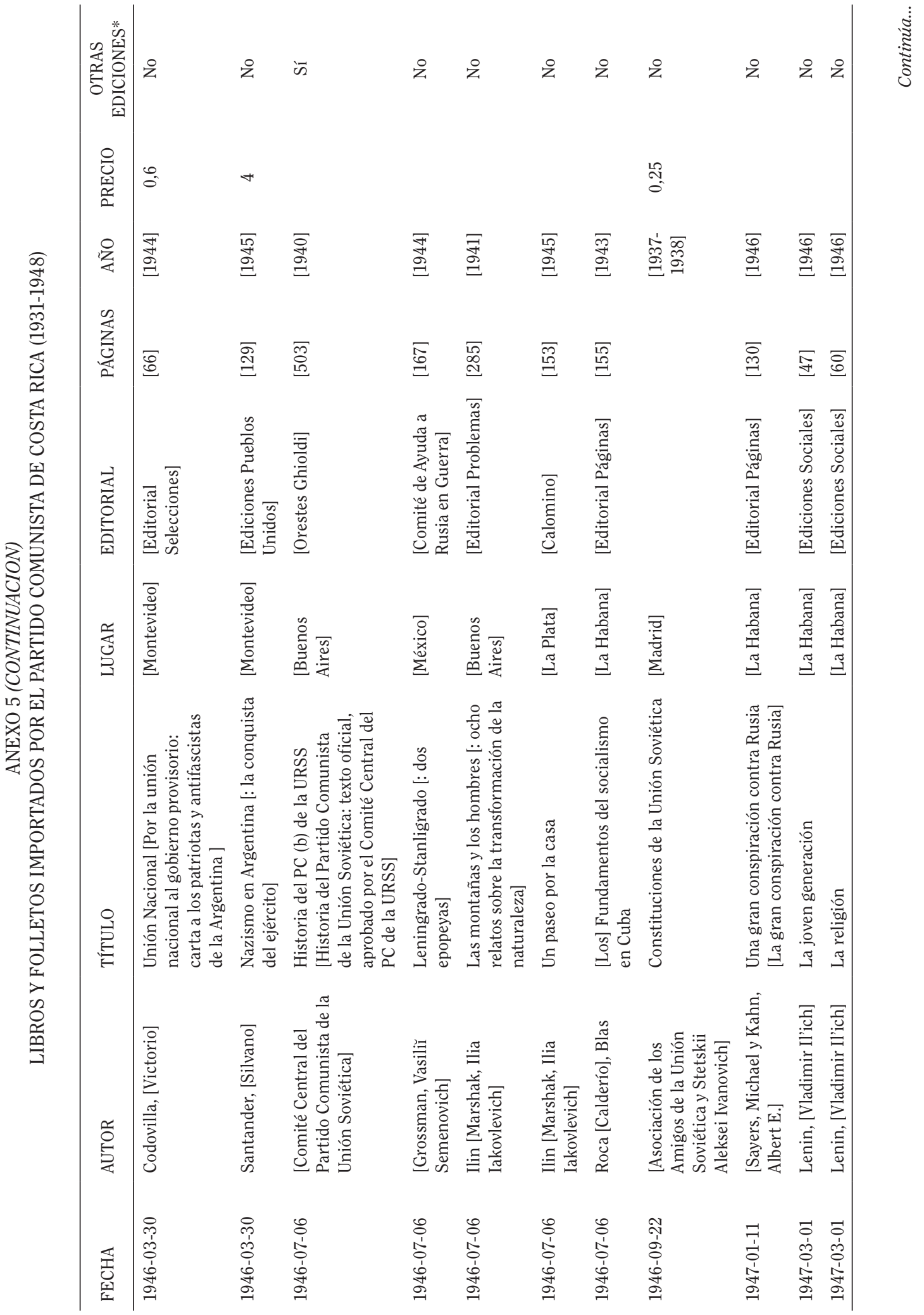




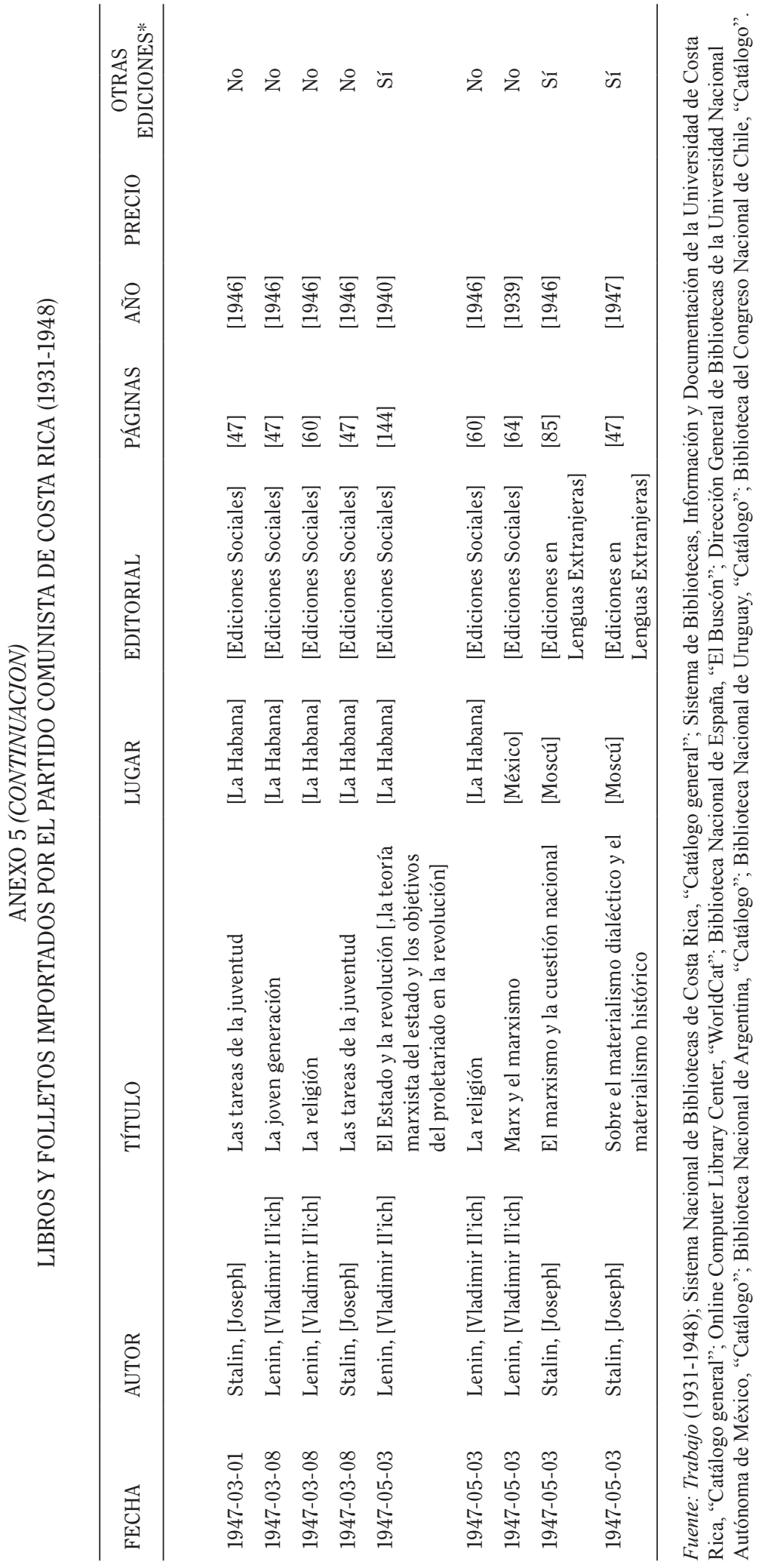


